\title{
Doubly Ionic Hydrogen Bond Interactions Within the Choline Chloride - Urea Deep Eutectic Solvent
}

\author{
Claire R. Ashworth, Richard P. Matthews, Tom Welton and Patricia A. Hunt* \\ Received (in $X X X, X X X)$ Xth $X X X X X X X X X 20 X X$, Accepted Xth $X X X X X X X X X 20 X X$ \\ ${ }_{5}$ DOI: 10.1039/b000000x
}

\begin{abstract}
Deep eutectic solvents (DESs) are exemplars of systems with the ability to form neutral, ionic and doubly ionic H-bonds. Herein, the pairwise interactions of the constituent components of the choline chloride urea DES are examined. Evidence is found for a tripodal $\mathrm{CH}^{\cdots} \cdot \mathrm{Cl}$ doubly ionic $\mathrm{H}$-bond motif. Moreover it is found that the covalency of doubly ionic H-bonds can be greater than, or comparable with, neutral 10 and ionic examples. In contrast to many traditional solvents, an "alphabet soup" of many different types of $\mathrm{H}$-bond $\left(\mathrm{OH} \cdots \mathrm{O}=\mathrm{C}, \mathrm{NH} \cdots \mathrm{O}=\mathrm{C}, \mathrm{OH}^{\cdots} \mathrm{Cl}, \mathrm{NH}^{\cdots}{ }^{\mathrm{Cl}}, \mathrm{OH} \cdots \mathrm{NH}, \mathrm{CH} \cdots \mathrm{Cl}, \mathrm{CH} \cdots \mathrm{O}=\mathrm{C}, \mathrm{NH} \cdots \mathrm{OH}\right.$ and $\mathrm{NH} \cdots \mathrm{NH}$ ) can form. These H-bonds exhibit substantial flexibility in terms of number and strength. It is anticipated that $\mathrm{H}$-bonding will have a significant impact on the entropy of the system and thus could play an important role in the formation of the eutectic. The 2:1 urea:choline-chloride eutectic point of this ${ }_{15} \mathrm{DES}$ is often associated with the formation of a $\left[\mathrm{Cl}(\text { urea })_{2}\right]^{-}$complexed anion. However, urea is found to form a $\mathrm{H}$-bonded urea[choline $]^{+}$complexed cation that is energetically competitive with $\left[\mathrm{Cl}(\text { urea })_{2}\right]^{-}$. The negative charge on $\left[\mathrm{Cl}(\text { urea })_{2}\right]^{-}$is found to remain localised on the chloride, moreover, the urea[choline $]^{+}$ complexed cation forms the strongest $\mathrm{H}$-bond studied here. Thus, there is potential to consider a urea $[\text { choline }]^{+} \cdot$ urea $[\mathrm{Cl}]^{-}$interaction.
\end{abstract}

\section{1. Introduction}

Hydrogen $(\mathrm{H})$-bonding is one of the most widely studied and yet contentious types of molecular interaction. There is a large amount of literature relating to the history and evolution of our understanding of $\mathrm{H}$-bonding. ${ }^{1}$ The notion that $\mathrm{H}$-bonds, $\mathrm{X}^{-}-$ ${ }_{25} \mathrm{H}^{+} \ldots \mathrm{Y}^{s^{-}}$, only form when $\mathrm{X}$ and $\mathrm{Y}$ are highly electronegative elements (e.g. $\mathrm{N}, \mathrm{O}, \mathrm{F}, \mathrm{Cl}$ ), or that these interactions are exclusively electrostatic in origin, has long been dispelled. ${ }^{2}$ Given the large number of different types of $\mathrm{H}$-bond, the formulation of a satisfactory generalised definition of the H-bond has proven

30 challenging. The most recent IUPAC definition of a H-bond is sufficiently broad to encapsulate a wide variety of interactions that could be (or have been) labelled as H-bonds. ${ }^{1,3}$ Emphasis is placed on providing evidence of H-bond formation, with a list of criteria and characteristics, both experimental and theoretical.

35 The "normal" H-bond, between two neutral species, has been studied in great depth., 2, 4 Similarly, the ionic H-bond, between a neutral molecule and a charged ion, has also been the subject of intense analysis. ${ }^{5,6}$ However, the H-bond between a cation and an anion, the doubly ionic H-bond, has largely been overlooked.

40 A recent critique of the area established the doubly ionic $\mathrm{H}-$ bond as a distinct, if not fully explored, class of H-bond. ${ }^{7}$ Although the doubly ionic H-bond was found to share many features with ordinary $\mathrm{H}$-bonds, features unique to the doubly ionic H-bond were also identified. Furthermore, it was suggested 45 that the formation of doubly ionic H-bonds is commonplace, particularly within the field of ionic liquids (ILs).

ILs are low melting point salts composed entirely of ions. Interest in ILs continues to grow due to the unusual combination of physico-chemical properties and the diverse range of 50 applications in which they can be exploited. ${ }^{8}, 9,10$ H-bonding is recognised to be one of the key interactions responsible for influencing the structuring and properties of ILs. ${ }^{11-17}$ Due to the vast number of possible ion combinations, the extent of $\mathrm{H}-$ bonding in ILs is highly system dependent. The potential to 55 modulate the relative contributions of electrostatics, dispersion and $\mathrm{H}$-bonding through ion design, and thus influence a range of physico-chemical properties, is one of the desirable attributes of ILs.

Many of the "simple" ILs (i.e. composed of discrete ions) most ${ }_{60}$ commonly employed at the lab scale, are currently prohibitively expensive for large-scale industrial application. A subclass of the eutectic branch of ILs, known as deep eutectic solvents (DESs), offers a highly promising and cheaper alternative to simple ILs for some applications.

65 Broadly, DESs are eutectic mixtures of two substances, usually a quaternary ammonium salt and a neutral "complexing agent", showing a notable decrease in the solid/liquid phase transition temperature relative to the ideal mixture of the starting materials. The room temperature liquid, or low melting point solid, that is 70 formed, exhibits typical physical properties of an IL but contains an unknown concentration of free neutral species. Due to the potential presence of neutral species, DESs have been referred to as IL analogues. ${ }^{18}$ 
Central to eutectic ILs is the concept of a "complexed ion"; interaction of a charged species with a neutral molecule to form a larger charged complex ([A] $\left.]^{-}+\mathrm{B} \rightarrow[\mathrm{A} . \mathrm{B}]^{-}\right)$. In a typical DES the cation is usually an asymmetric quaternary ammonium cation. ${ }_{5}$ Chloride is one of the most commonly employed counter anions, the only restriction on the anionic species is that it has the potential to act as a H-bond acceptor. ${ }^{19}$ There are several types of eutectic IL, with the majority categorised by Abbott et al according the nature of the neutral complexing agent. ${ }^{20,}{ }^{21}$ In the

10 following we will use DES to refer to eutectic mixtures of a quaternary ammonium salt and a neutral organic species capable of acting as a H-bond donor, e.g. amides ${ }^{19}$, carboxylic acids ${ }^{22}$ and polyols. $^{23,24}$

Many of the frequently employed ammonium salts and organic 15 complexing species (such as choline chloride $(\mathrm{ChCl})$ and urea respectively) are readily available as bulk commodity chemicals. As such, the number of studies focussing on the applications of DESs is steadily increasing and diversifying, application fields include catalysis, synthesis, novel materials preparation, 20 separations, drug solubilisation, electrodeposition and pretreatment of biomass. ${ }^{21,25,26}$

Within DESs H-bonding is of significant importance. For example, the complexed anion is proposed to form via H-bond interactions between the anion and the organic, H-bond donating, ${ }_{25}$ complexing agent. Spectroscopy (NMR and IR), mass spectrometry and recent ab-initio quantum chemical and molecular dynamics (MD) simulations have provided support for such interactions. ${ }^{19,27-29}$ Moreover, given that a DES is composed of neutral and both cationic and anionic components, there is the 30 potential for neutral, ionic and doubly ionic H-bonding.

A study of the interactions between the constituent components of a DES therefore provides an opportunity to compare the different types of H-bonding (neutral, ionic and doubly ionic) within a single, real system, in addition to 35 expanding our limited knowledge of DES systems.

The ChCl-urea mixture was one of the earliest DESs to be studied and has become one of the prototypical examples of this class of solvent. Whilst both components have high melting points $\left(\mathrm{ChCl} \mathrm{mp}=302^{\circ} \mathrm{C}\right.$, urea $\left.\mathrm{mp}=133^{\circ} \mathrm{C}\right)$, the eutectic mixture 40 of $\mathrm{ChCl}$ : urea at a 1:2 ratio has a reported freezing point of $12^{\circ} \mathrm{C} .{ }^{19}$ A representation of the possible speciation of the $\mathrm{ChCl}-$ urea DES system for this composition is shown in Scheme 1. For a given composition a DES will consist of $n$ cation: $n$ anion: $m$ organic complexing species, thus there is an additional level of ${ }_{45}$ complexity compared to a simple IL.

The relative conformational rigidity of urea, in comparison to some of the other commonly employed organic complexing agents (e.g. glycols) makes the ChCl-urea system a good starting point for a computational assay. Furthermore, ammonium ions ${ }_{50}$ are constituents of many ILs. Choline is an $\mathrm{OH}$ functionalised ion, therefore allowing for the examination of "ammonium" $\mathrm{H}$ bonds together with more traditional "OH" $\mathrm{H}$-bond interactions.
$[$ Cation $][\mathrm{X}]+\mathrm{H}$-bond donor $\rightleftharpoons[\text { Cation }]^{+}+[\mathrm{X} . \mathrm{H} \text {-bond donor }]^{-}$

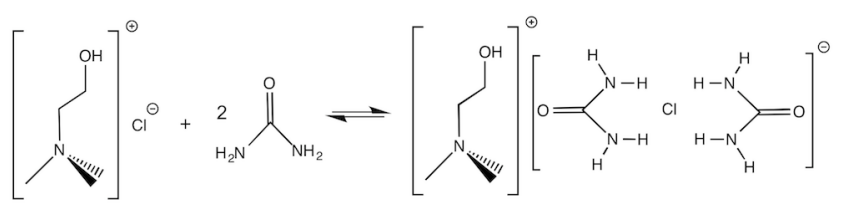

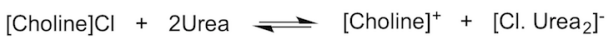

${ }_{55}$ Scheme 1. Possible complex formation in a DES. The ChCl-urea DES has a eutectic point at a $1: 2$ ratio.

Table 1. Criteria used to classify H-bonds, taken from reference 7.

\begin{tabular}{cccc}
\hline & Strong & Moderate & Weak \\
\hline $\begin{array}{c}\text { Energy H-bond/ } \\
\mathrm{kJmol}{ }^{-1}\end{array}$ & $63-167$ & $17-63$ & $<17$ \\
$\rho_{\mathrm{BCP}} / \mathrm{au}$ & $>0.05$ & $0.02-0.05$ & $0.002-0.02$ \\
& $\begin{array}{c}\text { very strong }>0.085 \\
\text { most often }-\mathrm{ve}\end{array}$ & + ve or $-\mathrm{ve}$ & + ve and small \\
Laplacian $\nabla^{2} \rho_{\mathrm{BCP}}$ & $\begin{array}{c} \\
\text { but can be }+\mathrm{ve}\end{array}$ & $<0.07$ \\
$\begin{array}{c}\text { Energy density } \mathrm{H}_{\mathrm{c}} \\
E^{(2)} / \mathrm{kJ} \mathrm{mol}^{-1}\end{array}$ & $\mathrm{Hc}<0$ & $\mathrm{Hc}<0$ & $\mathrm{Hc}>0$ \\
& $>150$ & $30-150$ & $<30$ \\
\hline
\end{tabular}

H-bonds have contributions from electrostatic, covalent and ${ }_{60}$ dispersion components, with the relative contribution of each determining the properties of the $\mathrm{H}$-bond. Although the majority of $\mathrm{H}$-bonds will be primarily electrostatic, the strongest $\mathrm{H}$-bonds are recognised as having a significant covalent contribution. ${ }^{30}$ The weakest H-bonds, may have a substantial dispersion ${ }_{65}$ component. ${ }^{30}$ The variable nature of the H-bond contributes to the difficulties associated with the qualification and quantification of $\mathrm{H}$-bond interactions.

Numerous experimental and theoretical properties have been used to classify H-bonds. For example, IR and ${ }^{1} \mathrm{H}$ NMR shifts, 70 bond lengths and angles are well established, as used in Jeffrey's popularised H-bond criteria. ${ }^{31}$

The total association energy, $E_{\mathrm{a}}$, of a H-bonded complex has frequently been used to quantify a H-bonded interaction. However, for doubly ionic systems, in particular, this is 75 unreliable, as the global association will be dominated by the Coulombic contribution. Thus, local descriptors of H-bonding are required. Common computational descriptors of the covalency of H-bonds are $\rho(\mathrm{r})$ and $E^{(2)} 4$

From a recent analysis of H-bonding, with specific focus on 80 ILs, a set of criteria, based on analysis of the topology of the electron density, $\rho(r)$, and the charge transfer component of the Natural Bond Orbital (NBO) analysis, $E^{(2)}$, were proposed for classification of doubly ionic H-bonds, Table $1 .^{7}$ These criteria shall be employed here to classify identified H-bonds, but with 85 one modification (further discussed in the ESI, section 1.3 Figure S2).

Within the computational community, Bader's Quantum Theory of Atoms in Molecules (QTAIM) has been employed extensively to investigate $\mathrm{H}$-bonding interactions. ${ }^{32,}{ }^{33}$ The ${ }_{90}$ presence of a bond critical point (BCP) between two atoms is indicative of a bonding interaction. The magnitude of $\rho(r)$ at a $\mathrm{BCP}\left(\rho_{\mathrm{BCP}}\right)$ has been linked to the strength and covalency of the interaction, and has previously been employed in the characterisation of H-bonds. ${ }^{4}$ 
NBOs are localised orbitals, typically on one or two centres. ${ }^{34}$ The NBO "picture" of the $\mathrm{X}^{-}-\mathrm{H}^{+} \cdots \mathrm{Y}^{-}$interaction usually involves the interaction of the lone pair on $\mathrm{Y}$ with the unoccupied $\mathrm{X}-\mathrm{H} \sigma^{*}$ orbital (ESI, Figure S1). The strength of this interaction ${ }_{5}$ can be quantified using $E^{(2)}$ (Equation 1) where $q_{i}$ is the donor orbital occupancy, $\varepsilon_{i}$ and $\varepsilon_{j}$ are the orbital energies and $F_{i j}$ is the off diagonal NBO Fock matrix element. $E^{(2)}$ stabilisation energies have been associated with the degree of covalency, and thus strength of $\mathrm{H}$-bonds. ${ }^{4}$

$$
E^{(2)}=q_{i} \frac{F(i, j)^{2}}{\varepsilon_{j}-\varepsilon_{i}}
$$

Equation 1

The amount of (NBO) charge transfer from the H-bond acceptor to $\mathrm{H}$-bond donor has previously been correlated with the 15 strength of neutral H-bond interactions. ${ }^{34,} 35$ Total charge transfer has also been correlated to the association energies of charged $\mathrm{H}-$ bonded complexes. ${ }^{15}$ However, the effects of charge transfer upon H-bond formation are complex and may differ for doubly ionic H-bond interactions. ${ }^{7}$

20 In this work we compare and contrast the possible pairwise associations between the fundamental building blocks of the ChCl-urea DES in detail, with a particular focus on H-bonding as a key contributor to physico-chemical properties of the eutectic mixture. Results and analysis are presented as follows: i). the 25 choline cation, ii). choline-chloride ion pairs, iii). the urea monomer and urea-urea dimers and iv). choline-urea pairs. Thus this work lays the foundation for understanding the more complex mixture of choline, chloride and $n$.urea. The importance of H-bonding in the formation of a complexed anion is 30 investigated; does the eutectic $\mathrm{mp}$ at a 1:2 ratio really reflect the formation of a $\left[\mathrm{Cl} \cdot \mathrm{urea}_{2}\right]$ complex? In the final section we undertake a comparison of the many types of $\mathrm{H}$-bonding interactions identified, comparing and contrasting these with more traditional H-bonds.

\section{${ }_{35}$ 2. Computational}

All calculations have been carried out with the Gaussian 09 (revisions B0.1 or D0.1) suite of programs. ${ }^{36}$ Initial geometries have been obtained employing Becke's three parameter exchange functional $^{37}$ with the correlation functional of Lee, Yang and ${ }_{40} \operatorname{Parr}^{38}$ (B3LYP) together with the $6-311+\mathrm{G}(\mathrm{d}, \mathrm{p})$ basis set. To account for dispersion effects Grimme's D2 dispersion correction $^{39}$ was employed with the B3LYP functional, hereafter referred to as B3LYP-D2. All species were then subjected to further optimisation at the B3LYP-D2 level in combination with ${ }_{45}$ the $6-311++\mathrm{G}(\mathrm{d}, \mathrm{p})$ basis set. This basis set has been shown to offer a reasonable compromise between cost and flexibility in computing accurate geometries and energies of $\mathrm{H}$-bonded systems. $^{40}$

All structures have been fully optimised under no symmetry 50 constraints. A pruned numerical integration grid of 99 radial shells and 590 angular points per shell was employed for all calculations in conjunction with the optimisation convergence criteria of $10^{-9}$ on the density matrix and $10^{-7}$ on the energy matrix. Frequency analysis has been performed for each structure 55 to confirm it as a minimum and provide zero-point energy corrections (ZPE). Basis set superposition errors (BSSE) for pairwise interactions have been obtained using the counterpoise correction method. ${ }^{41}$ All reported electronic energies, unless otherwise stated are BSSE and ZPE corrected at the B3LYP${ }_{60} \mathrm{D} 2 / 6-311++\mathrm{G}(\mathrm{d}, \mathrm{p})$ level. Relative energies, with and without, corrections can be found in the ESI. $\Delta G$ values have been evaluated at the B3LYP-D2/6-311++G(d,p) level and are available in the ESI.

To validate individual B3LYP-D2/6-311++G(d,p) level ${ }_{65}$ results, single point energies of the lowest energy conformers were computed at the MP2/aug-cc-pVTZ (BSSE corrected) and $\operatorname{CCSD}(\mathrm{T}) /$ aug-cc-pVDZ levels of theory. To allow for a direct comparison with the MP2 results, these energies are compared to B3LYP-D2/6-311++G(d,p) BSSE, but not ZPE corrected. 70 Individual ZPE corrections at the B3LYP-D2/6-311++G(d,p) level are provided in the ESI.

Population analysis has been carried out using the NBO method (version 5.9) ${ }^{42}$ and the electrostatic potential derived charges calculated employing the CHELPG $^{43}$ scheme. A 75 topological analysis of the electron density for selected systems within the QTAIM framework has been carried out using the AIMAll software. ${ }^{44}$ Further details relating to these methods are available in the ESI.

\section{Results and Discussion}

\section{${ }_{80}$ The Choline Cation}

The conformations and electronic structure of the choline cation (Figure 1 and ESI, Table S1) have been examined. The choline cation may be considered as a tetrahedron with four faces formed by the methyl/methylene groups of the quaternary ${ }_{85}$ ammonium head and a $\mathrm{CH}_{2} \mathrm{OH}$ chain extending from one of the vertices and partially blocking one of the faces (Figure 1a). Choline can adopt either a trans or gauche conformation with respect to the N-C-C-O torsion angle. The gauche conformation has previously been found to predominate in the solid, solution 90 and gas phases. ${ }^{45-47,61}$ In the gas phase the gauche conformer (Figure 1b) is found here to be $18 \mathrm{~kJ} \mathrm{~mol}^{-1}$ lower in energy than the trans conformer (Figure 1c), $\Delta G=15 \mathrm{~kJ} \mathrm{~mol}^{-1}$. An alterative trans conformation can be obtained with the $\mathrm{OH}$ group rotated (Figure 1d) which lies $23 \mathrm{~kJ} \mathrm{~mol}^{-1}$ higher in energy, $\Delta G=20 \mathrm{~kJ}$ ${ }_{95} \mathrm{~mol}^{-1}$. Association energies are referenced to the minimum energy gauche conformer.

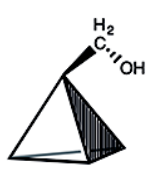

(a)

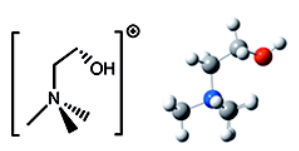

(b)

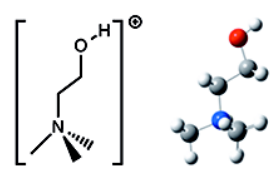

(c)

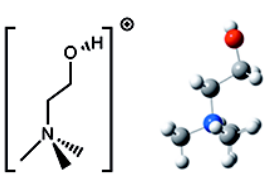

(d)
Figure 1. (a) A simplified representation of gauche choline as a tetrahedron with four "faces". Choline cation conformations: (b) Gauche, 100 
Table 2. Relative energies $\Delta E_{\text {rel }}$ in $\mathrm{kJ} \mathrm{mol}^{-1}$ of the $\mathrm{ChCl}$ ion pairs, the estimated difference in Coulomb energy $E_{\text {coulomb}}$, and the amount of charge transfer (CT) from the NBO and CHELPG population analyses.

\begin{tabular}{|c|c|c|c|c|}
\hline Ion Pair & $\underset{\mathrm{kJ} \mathrm{mol}^{-1}}{\Delta E_{\text {rel }}}$ & $\begin{array}{c}E_{\text {coulomb }} \\
\mathrm{kJ} \mathrm{mol}^{-1}\end{array}$ & $\mathrm{CT}(\mathrm{NBO}) / \mathrm{e}$ & CT (CHELPG)/ e \\
\hline A_ChG & 0.0 & 23.9 & 0.150 & 0.249 \\
\hline B_ChG & 0.8 & 4.4 & 0.130 & 0.250 \\
\hline C_ChG & 12.2 & 0.0 & 0.099 & 0.213 \\
\hline A_ChT & 21.5 & 7.0 & 0.102 & 0.231 \\
\hline D_ChG & 28.7 & 3.5 & 0.107 & 0.203 \\
\hline $\mathrm{E}^{-} \mathrm{ChG}$ & 29.8 & 4.4 & 0.111 & 0.217 \\
\hline B_ChT & 33.1 & 2.7 & 0.115 & 0.221 \\
\hline $\mathrm{C}^{-} \mathrm{ChT}$ & 37.5 & 18.5 & 0.108 & 0.193 \\
\hline
\end{tabular}

Table 3. Relative Gibbs free energy, $\Delta G_{\text {rel }}$, and $\Delta E_{\text {rel }}$ in $\mathrm{kJ} \mathrm{mol}^{-1}$ of the 5 three lowest energy $\mathrm{ChCl}$ ion pairs (employing B3LYP-D2/ 6-

$311++\mathrm{G}(\mathrm{d}, \mathrm{p})$ structures $)$. B3LYP-D2/6-311++G(d,p) BSSE corrected, MP2/aug-cc-pVTZ BSSE corrected, CCSD(T)/aug-cc-pVDZ.

\begin{tabular}{ccccc}
\hline & \multicolumn{4}{c}{} \\
\hline Ion Pair & $\begin{array}{c}\Delta G_{\text {rel }} \\
\text { B3LYP-D2 }\end{array}$ & $\begin{array}{c}\Delta E_{\text {rel }} \\
\text { B3LYP-D2 }\end{array}$ & $\begin{array}{c}\Delta E_{\text {rel }} \\
\text { MP2 }\end{array}$ & $\begin{array}{c}\Delta E_{\text {rel }} \\
\text { CCSD(T) }\end{array}$ \\
\hline A_ChG & 0 & 0 & 0 & 0 \\
B_ChG & 1 & 1 & 1 & 1 \\
C_ChG & 10 & 13 & 13 & 14 \\
\hline
\end{tabular}

Electronic factors result in stabilisation of the gauche 10 conformation. A favourable, non-specific, electrostatic interaction between the electronegative oxygen and the positive charge distributed over the ammonium head group is indicated by the computed partial charge distribution (ESI, Figure S3 and Table S2). ${ }^{46,} 47$ Moreover, the identification of a $\mathrm{CH}^{\circ} \cdots \mathrm{O}$ BCP with ${ }_{15} \rho_{\mathrm{BCP}}=0.016$ au (ESI, Figure S4a and Table S3) indicates the formation of an intramolecular H-bond. The neutral analogue of choline, $N, N$-dimethylethonolamine, exhibits a weaker H-bond, $\mathrm{CH} \cdots \mathrm{O}$ BCP $\rho_{\mathrm{BCP}}=0.010$ au (ESI, Figure S4b, Tables S3 and S4). Thus, we find that the anisotropic distribution of the overall $20+1$ charge within the cation facilitates the formation of H-bonds, over and above that of the neutral analogue.

\section{Choline Chloride Ion Pairs}

Choline chloride $(\mathrm{ChCl})$ is a key component of many DESs. To understand how the addition of a H-bond donor "disrupts" the ${ }_{25} \mathrm{ChCl}$ interaction, the nature of the local $\mathrm{ChCl}$ structuring must first be established. This study will also allow a comparison to other previously characterised and more common imidazolium based ILs.

\section{Structures}

30 Recognising choline cation as a functionalised "tetrahedron", $\mathrm{Cl}^{-}$was positioned at each of the unique faces of the gauche and trans conformers. Starting ion pair conformations with and without the involvement of the $\mathrm{OH}$ group were sampled, including conformations in which the $\mathrm{Cl}^{-}$interacted only with

${ }_{35} \mathrm{OH}$. Effort has been made to locate all potential low energy minima, for example, multiple alternative $\mathrm{H}$-bonding motifs were explored however, in all cases optimisations converged to the eight unique low energy $\mathrm{ChCl}$ conformers reported in Figure 2.
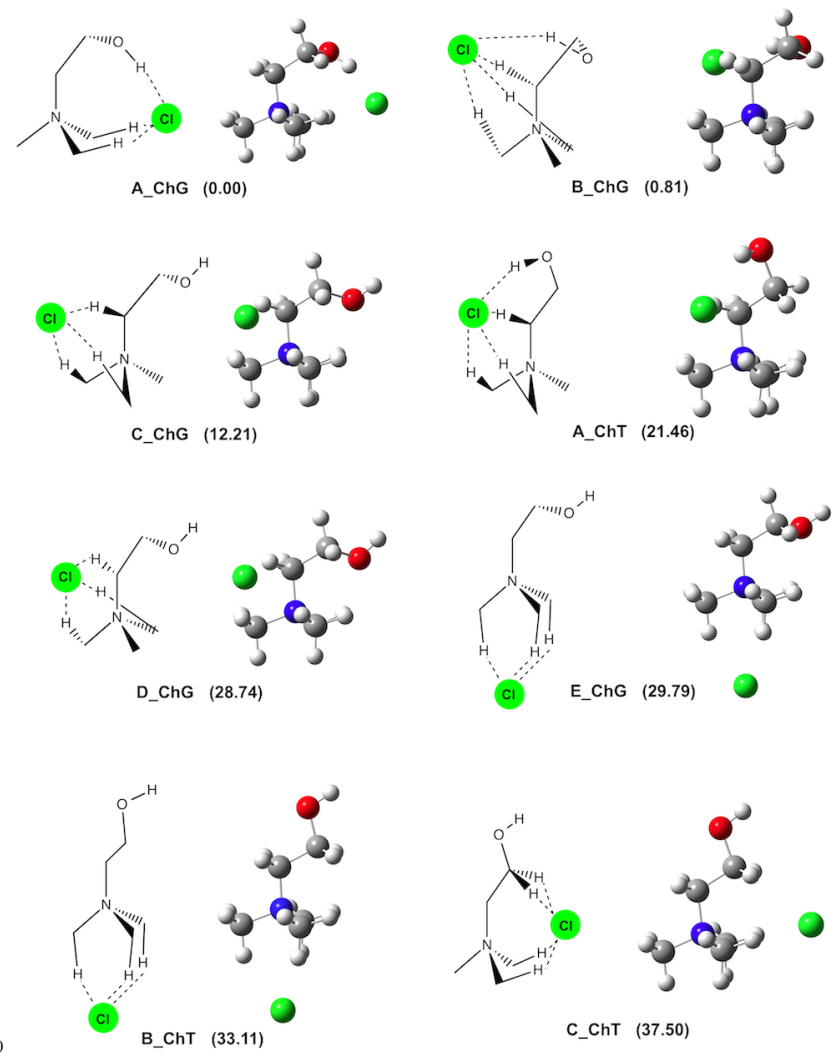

Figure 2. $\mathrm{ChCl}$ ion pairs, relative energy in $\mathrm{kJ} \mathrm{mol}^{-1}$.

Relative energies are listed in Table 2, further information including ZPE and BSSE corrections and $\Delta G$ values are available in the ESI, Table S5. The ion pairs are labelled according to the ${ }_{45}$ relative energy (alphabetically in ascending energy) for a given choline conformation, $\mathrm{ChG}$ and $\mathrm{ChT}$ denote gauche and trans choline respectively. For example, A_ChG is the lowest energy ion pair featuring gauche choline. The three lowest energy B3LYP-D2 optimised conformers were evaluated at the MP2 and ${ }_{50} \operatorname{CCSD}(\mathrm{T})$ levels, Table 3. These results confirm that B3LYP-D2 is a reasonable functional to employ.

Association energies are calculated as: $E_{\mathrm{a}}=E(\mathrm{ChCl})-E$ (gauche choline)-E(chloride) and range from -371 to $-409 \mathrm{~kJ} \mathrm{~mol}^{-1}$. These high values are typical for an ionic salt with an organic cation in ${ }_{55}$ the gas phase. ${ }^{48}$ The corresponding $E_{\mathrm{a}}$ for the most stable conformer is $-411 \mathrm{~kJ} \mathrm{~mol}^{-1}$ B3LYP-D2/6-311++G(d,p) (BSSE corrected), -419 $\mathrm{kJ} \mathrm{mol}^{-1} \mathrm{MP} 2 /$ aug-cc-pVTZ (BSSE corrected) and $-427 \mathrm{~kJ} \mathrm{~mol}^{-1} \operatorname{CCSD}(\mathrm{T}) /$ aug-cc-pVDZ, $G_{\mathrm{a}}=-419 \mathrm{~kJ} \mathrm{~mol}^{-1}$ B3LYP-D2/6-311++G(d,p).

${ }_{60}$ Analysis of the ion-pair structures shows that there are a number of stable positions available for the chloride anion around a trans or gauche choline cation. A chloride anion can "sit" at the centre of one of the three unhindered tetrahedron faces of the cation, (B-E_ChG, A-B_ChT) or at the hindered face (A_ChG, ${ }_{65} \mathrm{C}_{-} \mathrm{ChT}$ ). Similar structures have been found experimentally within crystal structures. ${ }^{49}$

All of the $\mathrm{ChCl}$ structures exhibit multiple H-bonding interactions. The lowest energy conformers feature a $\mathrm{OH} \cdots \mathrm{Cl}$ interaction, however no stable structure with an isolated linear

${ }_{70} \mathrm{OH} \cdots \mathrm{Cl}$ interaction could be found. Slightly higher in energy are ion pairs that feature only $\mathrm{CH} \cdots \mathrm{Cl}$ interactions; the lowest energy 
structure of this type (C_ChG) is only $12 \mathrm{~kJ} \mathrm{~mol}^{-1}$ above A_ChG. A recurring motif within these ion pairs is a "tripodal" interaction of the chloride with three hydrogen atoms. This motif has been observed previously in a number of systems, particularly those 5 featuring quaternary ammonium cations. ${ }^{45}, 50-53$ However, the significance, and nature of, this structural motif has largely been overlooked.

\section{Ionic-interactions}

Insight into the ionic component of the $\mathrm{ChCl}$ interaction can be 10 obtained from a partial charge analysis; NBO and CHELPG charge transfer are reported in Table 2. We have evaluated an effective Coulomb interaction by assuming the ions are point charges of $\pm 0.9 e$ (NBO), the positive charge of choline located at the nitrogen centre and the negative charge located at the $\mathrm{Cl}$ 15 anion. This crude approximation recovers $\approx 300 \mathrm{~kJ} \mathrm{~mol}^{-1}$, ESI Table S6. The separation $(\Delta \mathrm{r})$ between the nitrogen and chloride ranges from $3.84 \AA$ (A_ChG) to $3.55 \AA$ (C_ChG), leading to a difference in the electrostatic potential energy of $\approx 24 \mathrm{~kJ} \mathrm{~mol}^{-1}$, Table 2 Thus, as expected, the bulk of the ion-pair association 20 energy is recovered by pure electrostatics. However, the variation in energy between conformers is not recovered by considering the ions as point charges, indicating the importance of local, specific (atom-atom) Coulombic interactions and $\mathrm{H}$ bonding. This has implications for charge distributions employed 25 in MD potentials.

The two lowest energy ion pairs exhibit the largest charge transfer, Table 2. The amount of NBO charge transfer from the $\mathrm{H}$-bond acceptor has been previously linked to the strength of $\mathrm{H}$ bond formation. ${ }^{34,}{ }^{35}$ Charge transfer from chloride in the ion 30 pairs ranges from $0.099-0.150 e$ using the NBO scheme, or 0.193 - 0.250e employing the CHELPG scheme. The larger magnitude of charge transfer obtained with the ESP charge partitioning methods has been previously observed in other systems. ${ }^{54}$ However, the range in the charge transfer $(0.051 e$ and $0.057 e$ for ${ }_{35} \mathrm{NBO}$ and CHELPG respectively) is very similar.

\section{H-Bonding}

QTAIM molecular graphs for representative conformers A_ChG and E_ChG, are shown in Figure 3. Additional information relating to $\mathrm{H}$-bonds within all of the $\mathrm{ChCl}$ ion pairs is

40 provided in the ESI, Table S7. There are two kinds of H-bond formed between the choline cation and $\mathrm{Cl}$ anion. A more traditional $\mathrm{OH} \cdots \mathrm{Cl} \mathrm{H}$-bond (the $\mathrm{OH}$ only mildly affected by the charged ammonium centre), and doubly ionic $\mathrm{CH} \cdots \mathrm{Cl} \mathrm{H}$-bonds facilitated by the presence of significant charge.

45 The weak intramolecular $\mathrm{CH}^{\cdots} \cdots \mathrm{OH}$ H-bond is preserved within gauche choline, e.g. Figure 3a. For the ion pairs containing $\mathrm{OH}^{\cdots} \mathrm{Cl}$ interactions the strength of the $\mathrm{OH} \cdots \mathrm{Cl} \mathrm{H}$-bond varies as A_ChG $>$ B_ChG $>$ A_ChT, with $\rho_{\text {BCP }}$ values of $0.034,0.026$ and 0.013 au respectively. This is concurrent with the increase in so the $\mathrm{OH} \cdots \mathrm{Cl} \mathrm{H}$-bond length. Thus, a graduated series of $\mathrm{H}$-bonds is possible depending on the local arrangement of the cation and anion.

BCPs are located for each of the $\mathrm{CH} \cdots \mathrm{Cl}$ interactions, e.g. Figure 3b. Tripodal arrangements of positive hydrogen atoms ${ }_{55}$ are presented to an approaching anion and three $\mathrm{CH} \cdots \mathrm{Cl} \mathrm{H}$-bonds form. Within $\mathrm{E} \mathrm{ChG}$, each of the individual $\mathrm{CH} \cdots \mathrm{Cl}$ interactions is weak (mean $\rho_{\mathrm{BCP}}=0.020 \mathrm{au}$ ), but the sum of $\rho_{\mathrm{BCP}}$ for the three $\mathrm{CH} \cdots \mathrm{Cl}$ interactions is 0.059 au. The mean (evaluated over all the stable conformers) $\rho_{\mathrm{BCP}}$ is 0.018 au but ranges from $0.008-$
${ }_{60} 0.022 \mathrm{au}$. Thus, the majority of the individual $\mathrm{CH} \cdots \mathrm{Cl} \mathrm{H}$-bonds fall within the weak H-bond category identified in Table 1.

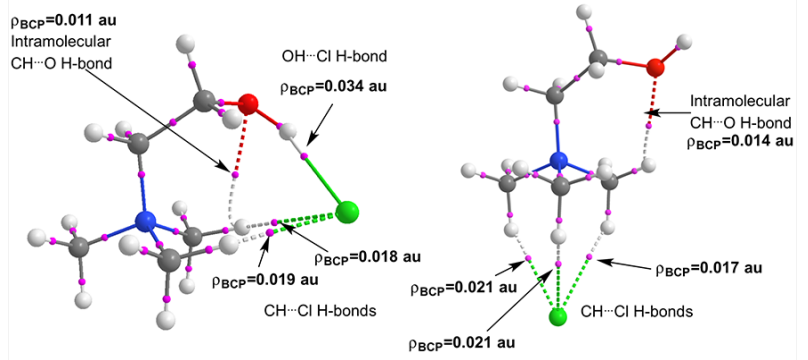

(a)

(b)

Figure 3. QTAIM molecular graphs of (a) A ChG and (b) E ChG. BCPs shown as pink dots, RCPs and CCPs omitted for clarity.

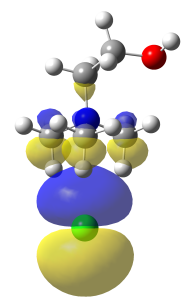

(a)

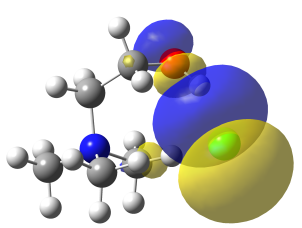

(b)

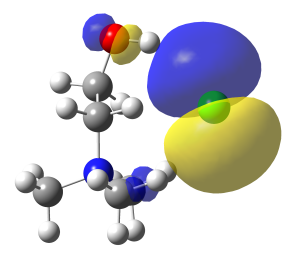

(c)
Figure 4. HOMO-2 of (a) E_ChG, (b) A_ChG and (c) A_ChT generated at the 0.02 au isosurface.

For comparison, chloroform $\left(\mathrm{Cl}_{3} \mathrm{CH}\right)$ interacting with $\mathrm{Cl}$ forms an anionic, linear medium strength $\mathrm{CH} \cdots \mathrm{Cl} \mathrm{H}$-bond, with ${ }_{70} \rho_{\mathrm{BCP}}=0.033 \mathrm{au}$, (ESI, Figure S5). Thus, the doubly-ionic tripodal H-bond arrangement with total $\rho_{\mathrm{BCP}}=0.059$ is highly competitive with an ionic linear $\mathrm{CH} \cdots \mathrm{Cl}$ interaction. The preference for a tripodal over a linear arrangement has also recently observed for $\mathrm{CH} \cdots \mathrm{O} \mathrm{H}$-bond interactions between $75\left[\mathrm{NMe}_{4}\right]^{+}$and $\mathrm{N}$-methylacetamide. ${ }^{51}$ Thus, while each individual $\mathrm{CH} \cdots \mathrm{Cl} \mathrm{H}$-bond is weak, there is substantial strength in a tripodal arrangement of doubly ionic $\mathrm{CH} \cdots \mathrm{Cl} \mathrm{H}$-bonds.

Analysis of ion pair MOs can be used to evaluate the degree of orbital interaction in the different conformers. For ion pairs with 80 only $\mathrm{CH} \cdots \mathrm{Cl}$ interactions, the HOMO, HOMO-1 and HOMO-2 are dominated by the three $3 \mathrm{p}$ AOs of the chloride anion, with a minimal contribution from the $\mathrm{C}-\mathrm{H}$ units. The HOMO-2 of ion pair E_ChG is presented in Figure 4a and shows the interaction between the tripodal face formed of $\mathrm{C}-\mathrm{H}$ based fragment orbitals 85 and a pAO of chloride. The localisation of orbital contributions on primarily one fragment confirms this interaction is highly ionic in nature.

For ion pairs with an $\mathrm{OH} \cdots \mathrm{Cl}$ interaction there is the additional involvement of an $\mathrm{OH}$ based fragment orbital in the HOMO-2 ${ }_{90}$ Figure $4 \mathbf{b}$ and $4 \mathbf{c}$. When the cation conformer is gauche the orbital interaction is linear and there is a slightly more significant contribution from the $\mathrm{OH}$ group, Figure 4b. In contrast, for a trans conformer, Figure $\mathbf{4 c}$, the orbital interaction is "bent", resulting in reduced orbital overlap, moreover $\rho_{\mathrm{BCP}}$ is also ${ }_{95}$ reduced. Thus, the gauche conformer is better able to maintain a stronger linear $\mathrm{OH} \cdots \mathrm{Cl} \mathrm{H}$-bond. This may explain in part the (generally) slightly greater stability of the gauche as compared to the trans conformers. 


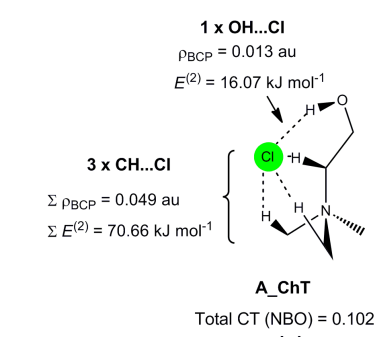

(a)

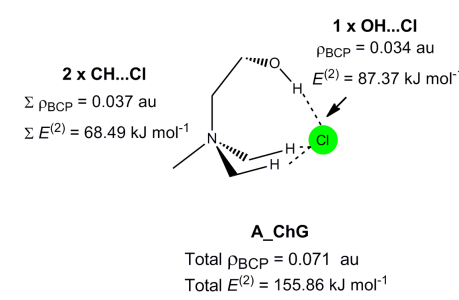

(c)

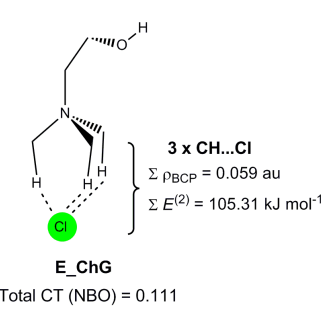

(b)

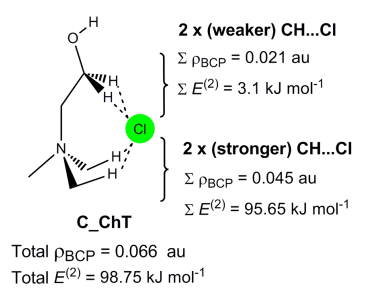

(d)
Figure 5. H-bonding in ion pairs (a) A_ChT, (b) E_ChG, (c) A_ChG and (d) C_ChT.

The $\mathrm{OH}$ functional group is generally considered capable of ${ }_{5}$ forming very strong $\mathrm{H}$-bonds, while $\mathrm{CH}$ units are generally considered to form only weak H-bonds. A number of these key H-bonding motifs are compared in Figure 5, A_ChT $(+21 \mathrm{~kJ}$ $\mathrm{mol}^{-1}$, Figure 5a) and $\mathrm{E} \_\mathrm{ChG}\left(+30 \mathrm{~kJ} \mathrm{~mol}^{-1}\right.$, Figure 5b). Based on $\rho_{\mathrm{BCP}}$, the $\mathrm{OH} \cdots \mathrm{Cl}$ H-bond in A_ChT $(0.013 \mathrm{au})$ is weaker than 10 the average $\mathrm{CH} \cdots \mathrm{Cl}$ H-bond $(0.018 \mathrm{au})$. The total sum of $\rho_{\mathrm{BCP}}$ in A_ChT is almost the same as in E_ChG, and the sum of the $E^{(2)}$ values for the $n_{\mathrm{Cl}} \rightarrow \sigma_{\mathrm{X}-\mathrm{H}} *$ interactions in $\mathrm{E}$ ChG is $\approx 20 \mathrm{~kJ} \mathrm{~mol}^{-1}$ greater than in A_ChT. The total charge transfer is also greater within E_ChG than A_ChT. Furthermore, the $\mathrm{OH}$ group 15 fragment orbital contribution to the HOMO-2 is approximately equal to each of the individual $\mathrm{CH}$ fragment orbital contributions in the HOMO-2 of E_ChG.

These results indicate that the methyl groups closest to or "carrying" the cationic positive charge (within choline) are 20 capable of entering into $\mathrm{H}$-bonds that are stronger than the $\mathrm{OH}$ group. Moreover, when combined in a recurring tripodal arrangement a strong $\mathrm{H}$-bond motif is formed. Thus, naïve concepts of H-bonding, applicable in neutral systems, are best treated with caution when applied to ion-pairs that can form 25 multiple, doubly ionic H-bonds.

The H-bonding within A_ChG $\left(0 \mathrm{~kJ} \mathrm{~mol}^{-1}\right.$, Figure 5c) and C_ChT (+38 kJ mol ${ }^{-1}$, Figure 5d) illustrates two ends of a spectrum; a smaller number of stronger H-bonds as opposed to a larger number of weaker H-bonds. Maximisation of the number 30 of H-bonds is sometimes used to rationalise the relative energy of conformers, however in this case the reverse is true. Within C_ChT, four $\mathrm{CH} \cdots \mathrm{Cl} \mathrm{H}$-bonds are formed (and no $\mathrm{OH} \cdots \mathrm{Cl} \mathrm{H}$ bond), while within A_ChG a stronger $\mathrm{OH} \cdots \mathrm{Cl}$ interaction and only two $\mathrm{CH} \cdots \mathrm{Cl} \mathrm{H}$-bonds are formed. However, consideration

35 of the number and strength of all the individual H-bond interactions is consistent with concepts of maximising $\mathrm{H}$ bonding. A_ChG, the most stable conformer has a larger total $\rho_{\mathrm{BCP}}$ and $\mathrm{E}^{(2)}$, Figure 5.
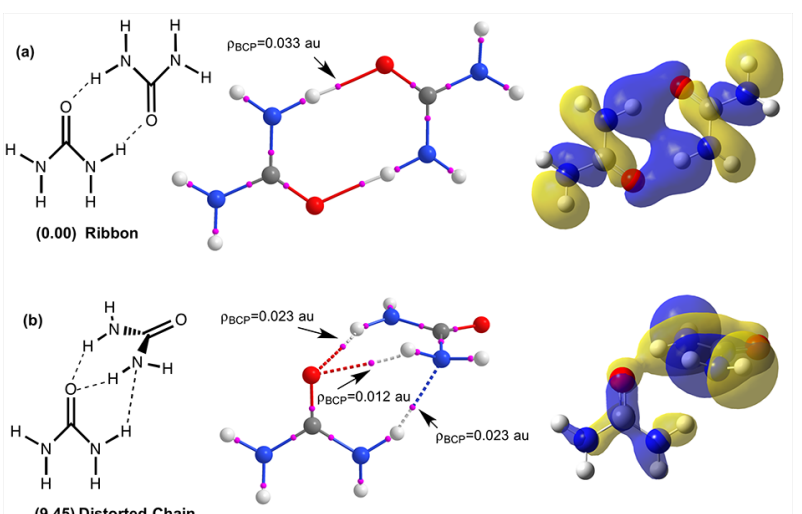

40

Figure 6. Urea conformers (relative energy in $\mathrm{kJ} \mathrm{mol}^{-1}$ ), QTAIM molecular graphs (pink dots are BCPs) and H-bond formation MOs (generated at the $0.02 \mathrm{au}$ isosurface) for the (a) ribbon and (b) distorted chain dimers.

45 A number of key results emerge from the $\mathrm{ChCl}$ analysis. There is a wide range of stable conformers that can be accessed. Considering the ions as global point charges centred at $\mathrm{N}$ or $\mathrm{Cl}$ does not correlate with the individual conformer energy ordering. Each conformer finds a balance between maximising very local, ${ }_{50}$ specific (atom-atom) Coulomb and H-bonding interactions. While the expected strong $\mathrm{OH} \cdots \mathrm{Cl} \mathrm{H}$-bond occurs, the strength of this interaction varies over a significant range for different conformers, and may offer a handle for fine tuning molecular properties. A recurring novel feature is the tripodal $\mathrm{CH} \cdots \mathrm{Cl} \mathrm{H}-$ ${ }_{55}$ bond motif, where the three concerted doubly ionic $\mathrm{CH} \cdots \mathrm{Cl}$ interactions can contribute significant stability and dominate a single $\mathrm{OH} \cdots \mathrm{Cl}$ interaction. It is evident there is a very fine balance between a larger number of concerted but weaker $\mathrm{H}$ bonds and a smaller number of individual but stronger H-bonds, ${ }_{60}$ which allow this system to be highly fluxional.

\section{Urea Monomer and Urea-Urea Dimers}

At the eutectic composition the mol\% of urea is greater than the $\mathrm{mol} \%$ of $\mathrm{ChCl}$, thus, statistically urea-urea interactions are probable. Moreover, we need to establish how competitive urea${ }_{65}$ urea interactions are with respect to other potential pairwise interactions, both in terms of energy and H-bonding.

The gas phase geometries of amides have been studied extensively both computationally and experimentally. ${ }^{55-59}$ The heavy atoms $(\mathrm{O}-\mathrm{C}-\mathrm{N})$ of urea are co-planar, but the $\mathrm{NH}_{2}$ groups 70 are pyramidal. This results in three key geometries, $C_{2}, C_{2 v}$ and $C_{s}$ urea (ESI, Figure S6). ${ }^{56-58}$ The energy difference between the three conformers is small, and depends on the level of theory. ${ }^{58}$ $C_{2}$ and $C_{s}$ urea computed at the B3LYP-D2/6-311++G(d,p) level are found to be essentially degenerate after ZPE correction (ESI, 75 Table S8). The $C_{2 v}$ urea was found to have two imaginary frequencies, consistent with literature reports. ${ }^{57,}{ }^{58}$ For consistency, association energies have been calculated using the slightly lower energy $C_{2}$ structure as a reference.

Urea dimers exhibit "traditional" neutral H-bonds, and in 80 forming a dimer, urea acts as both an effective H-bond donor and H-bond acceptor. Gas phase dimers of urea have previously been investigated, ${ }^{58,60}$ and thus we restrict our discussion to features relevant for this study. 


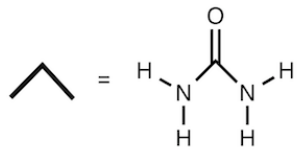

(a)

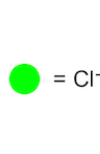

(b)

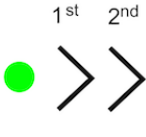

(c)
Figure 7. Simplified representation of (a) urea and (b) chloride. Concept of a coordination sphere with respect to chloride shown in (c).

The lowest energy dimer is a symmetric planar "ribbon" ${ }_{5}$ conformer, $E_{\mathrm{a}} \approx-59 \mathrm{~kJ} \mathrm{~mol}^{-1}$ (Figure 6a and ESI, Table S9). $E_{\mathrm{a}}$ at the B3LYP-D2/6-311++G(d,p) (BSSE corrected), MP2/aug-ccpVTZ (BSSE corrected) and CCSD(T)/aug-cc-pVDZ levels are $66,-56$ and $-63 \mathrm{~kJ} \mathrm{~mol}^{-1}$ respectively. However, $\Delta G_{\mathrm{a}}$ is $-17 \mathrm{~kJ}$ $\mathrm{mol}^{-1}$ at the B3LYP-D2/6-311++G(d,p) level, indicating that the 10 entropic effect of H-bonding is substantial. Formation of an additional $\mathrm{N}-\mathrm{H} \cdots \mathrm{N}$ H-bond in the gas phase dimers leads to a distorted chain conformer $9 \mathrm{~kJ} \mathrm{~mol}^{-1}$ higher in energy $(\Delta G$ is similar, $9 \mathrm{~kJ} \mathrm{~mol}^{-1}$ ), Figure $6 \mathbf{b}$.

$\mathrm{H}$-bonding is evident in both dimer conformers. In the ribbon 15 conformer two single $\mathrm{NH} \cdots \mathrm{O}=\mathrm{C} \mathrm{H}$-bonds are formed, each with $\rho_{\mathrm{BCP}}=0.033 \mathrm{au}$, Figure 6a (full details of the QTAIM analysis are provided in the ESI, Table S10). These BCPs are essentially equivalent to the strongest $\mathrm{OH} \cdots \mathrm{Cl}$ interaction $\left(\rho_{\mathrm{BCP}}=0.034 \mathrm{au}\right)$, found in $\mathrm{ChCl}$ A_ChG conformer. The sum for the combined $\mathrm{H}-$ 20 bonding interactions is $\Sigma \rho_{\mathrm{BCP}}=0.066$ au. The effective MO interaction between the two fragments, Figure 6a, indicates delocalisation over the whole system. The sum of the stabilisation energies $E^{(2)}$ for $n_{\mathrm{O}} \rightarrow \sigma_{\mathrm{N}-\mathrm{H}} *$ from one urea to the other is $69 \mathrm{~kJ} \mathrm{~mol}^{-1}$. As the interaction is symmetric, the 25 stabilisation energies between two urea units is $137 \mathrm{~kJ} \mathrm{~mol}^{-1}$.

Within the distorted chain a chelating H-bond motif is observed where the oxygen of one urea interacts with two different hydrogen atoms of the other urea. The sum of the $\rho_{\mathrm{BCP}}$ values at the two $\mathrm{NH} \cdots \mathrm{O}=\mathrm{C}$ BCPs $(0.035 \mathrm{au})$ approximately 30 equates to the $\rho_{\mathrm{BCP}}$ value of a single $\mathrm{NH}^{\cdots} \mathrm{O}=\mathrm{C}$ H-bond in the ribbon. With a $\rho_{\mathrm{BCP}}$ value of $0.023 \mathrm{au}$, the $\mathrm{NH} \cdots \mathrm{N}$ interaction is equal to the stronger of the two $\mathrm{NH} \cdots \mathrm{O}=\mathrm{C} \mathrm{H}$-bonds in the distorted chain. The contribution from each fragment to a given $\mathrm{MO}$ is very unequal, Figure $\mathbf{6 b}$ and the $E^{(2)}$ delocalisation only 35 totals $63.2 \mathrm{~kJ} \mathrm{~mol}^{-1}$. Thus, there is a reduced degree of delocalisation within the distorted chain motif.

\section{Urea-Chloride Complexed Anions}

The interaction of urea with chloride leads to the formation of anionic H-bonds. In the absence of additional information, the 40 eutectic $\mathrm{mp}$ which occurs at a ratio of 1:2 ([choline]Cl:urea), has suggested the formation of a complexed anion, $\left[\mathrm{Cl}(\text { urea })_{2}\right]^{-}$. Within $\left[\mathrm{Cl}(\text { urea })_{2}\right]^{-}$it is anticipated that the negative charge on $\mathrm{Cl}^{-}$is delocalised reducing cation-anion interactions within the DES and lowering the melting point. A computational study 45 allows us to investigate more fully the nature of this potential complexed anion. Moreover, the question arises as to why $[\mathrm{Cl}(\text { urea })]^{-}$or $\left[\mathrm{Cl}(\text { urea })_{3}\right]^{-}$are not favoured, and hence a comparison with urea-urea interactions is undertaken.
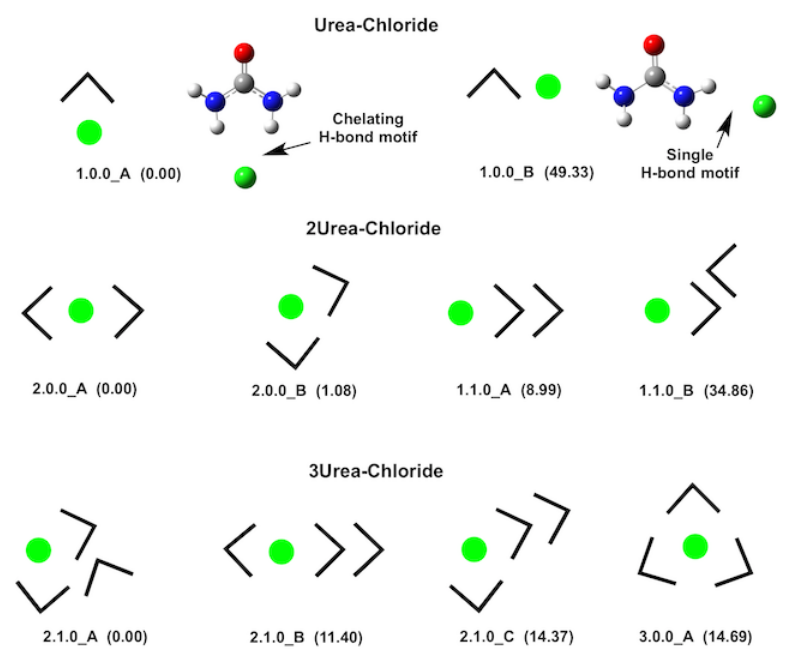

3.0.0_A (14.69)
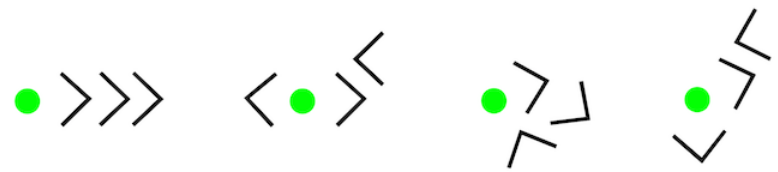

1.1.1_A (23.68)

2.1.0_D (33.25)

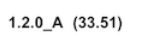

2.1.0_E (33.99)

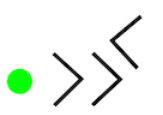

1.1.1_B (41.06)

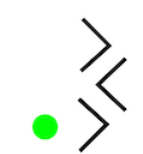

1.1.1_c (55.58)

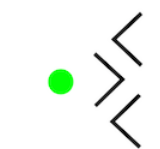

1.2.0_B (71.73)
50

Figure 8. Simplified depiction of urea-chloride clusters. Structures named using shell model: X.Y. Z. Relative energy in $\mathrm{kJ} \mathrm{mol}^{-1}$.

Urea-chloride interactions have been considered for systems of composition n.urea: $\mathrm{Cl}^{-}(\mathrm{n}=1-3)$. Starting structures with $\mathrm{Cl}-$ ${ }_{55}$ positioned to interact with either anti and/or syn $\mathrm{NH}$ units were optimised. With one exception, all of these structures converged to a single chelating [Cl(urea) $]^{-}$motif (to be discussed shortly). Starting structures for the $\left[\mathrm{Cl}(\text { urea })_{2}\right]^{-}$and $\left[\mathrm{Cl}(\text { urea })_{3}\right]^{-}$clusters were built using the most stable chelating urea- $\mathrm{Cl}^{-}$motif ${ }_{60}$ combined with both the ribbon and chain urea-urea dimers as building blocks. Additional structures were constructed by forming $\mathrm{H}$-bonds between urea molecules, and a number of more random structural motifs were generated. In building the input structures for the larger clusters many different combinations of ${ }_{65}$ the solvation shell and two urea-urea interaction motifs were explored.

A simplified representation of clusters, which emphasises a shell filling model of solvation, has been employed, Figure 7. In the solvation shell representation clusters are labelled as X.Y.Z, 70 where $X, Y$ and $Z$ are the number of urea molecules in the $1^{\text {st }}, 2^{\text {nd }}$ and $3^{\text {rd }}$ coordination shells respectively. Cluster structural motifs are reported in Figure 8, geometries can be found in the ESI, Figure $\mathbf{S 7}$ and relative energies in Table 4. ZPE corrections are generally $\approx 2,1$ and $7 \mathrm{~kJ} \mathrm{~mol}^{-1}$, while BSSE corrections are $\approx 1,4$ 75 and $6 \mathrm{~kJ} \mathrm{~mol}^{-1}$ for the $\left[\mathrm{Cl}(\text { urea })_{\mathrm{n}}\right]^{-} \mathrm{n}=1,2$ and 3 clusters respectively. Additional data, including $\Delta G$ values, can be found in the ESI, Table S11. 
Table 4. Relative energies $\left(\mathrm{kJ} \mathrm{mol}^{-1}\right)$ of the $n$.urea-chloride clusters $(n=1$ 3) and magnitude of charge transfer from chloride (CT)

\begin{tabular}{|c|c|c|c|}
\hline Complex & $\Delta E_{\text {rel }} / \mathrm{kJ} \mathrm{mol}^{-1}$ & CT (NBO) / e & CT (CHELPG) / \\
\hline $1.0 .0 \mathrm{~A}$ & 0.00 & 0.076 & 0.109 \\
\hline $1.0 .0 \_\mathrm{B}$ & 49.33 & 0.040 & 0.060 \\
\hline 2.0.0_A & 0.00 & 0.097 & 0.136 \\
\hline $2.0 .0 \_\mathrm{B}$ & 1.08 & 0.107 & 0.185 \\
\hline 1.1.0_A & 8.99 & 0.098 & 0.130 \\
\hline 1.1.0_B & 34.86 & 0.080 & 0.108 \\
\hline 2.1.0_A & 0.00 & 0.105 & 0.171 \\
\hline 2.1.0_B & 11.40 & 0.106 & 0.125 \\
\hline 2.1.0_C & 14.37 & 0.117 & 0.194 \\
\hline 3.0.0_A & 14.69 & 0.104 & 0.178 \\
\hline 1.1.1_A & 23.68 & 0.103 & 0.137 \\
\hline 2.1.0_D & 33.25 & 0.101 & 0.128 \\
\hline 1.2.0_A & 33.51 & 0.104 & 0.136 \\
\hline 2.1.0_E & 33.99 & 0.111 & 0.183 \\
\hline 1.1.1_B & 41.06 & 0.097 & 0.126 \\
\hline 1.1.1_C & 55.58 & 0.079 & 0.106 \\
\hline 1.2.0_B & 71.73 & 0.083 & 0.094 \\
\hline
\end{tabular}

The first urea molecule coordinates to chloride (1.0.0_A, ${ }_{5}$ Figure 8) through a chelating H-bond motif with urea acting as a double H-bond donor. The single H-bond motif, 1.0.0_B, is significantly higher in energy $\left(49 \mathrm{~kJ} \mathrm{~mol}^{-1}\right)$.

The computed dipole moment of $C_{2}$ urea is $3.9 \mathrm{D}$, thus, there is a significant ion-dipole contribution to the association energy. 10 Employing the ion-dipole equation for complex 1.0.0_A; using $1 e$ on $\mathrm{Cl}^{-}$, the dipole moment of $C_{2}$ urea, and taking $3.78 \AA$ as the $\mathrm{Cl} \cdots \mathrm{C}_{\text {urea }}$ intermolecular separation, gives an estimate of the electrostatic interaction of $-79 \mathrm{~kJ} \mathrm{~mol}^{-1}$. Thus the strong association energy associated with these clusters is attributable to 15 both highly chelating H-bonds and ion-dipole based interactions.

A second urea molecule can either interact directly with chloride (i.e. enter the $1^{\text {st }}$ coordination shell), giving rise to structures 2.0.0_A (Figure 9a) or 2.0.0_B (Figure 9b) or interact with urea (i.e. enter the $2^{\text {nd }}$ coordination shell), giving rise to

20 structures 1.1.0_A (Figure 9c) or 1.1.0_B. Similarly, a third urea molecule can either be placed in the $1^{\text {st }}$ coordination shell 3.0.0 A (Figure 9e), the $2^{\text {nd }}$ coordination shell e.g. 2.1.0_A (Figure 9d), or, if added to one of the 1.1.0 structures, enter the $3^{\text {rd }}$ coordination shell and produce one of the 1.1.1 structures. ${ }_{25}$ The geometry of selected structures is discussed more fully in the ESI, Figures S8 and S9.

Analysis of $\Delta G$ values for $\left[\mathrm{Cl}(\text { urea })_{2}\right]^{-}$clusters (ESI, Table S11) leaves the ordering unchanged but stabilises 2.0.0_A slightly relative to the other conformers. However, including 30 temperature and entropic effects changes the coordination shell preferences for $\left[\mathrm{Cl}(\text { urea })_{3}\right]^{-}$and 2.1.0_A $\left(\Delta G+16 \mathrm{~kJ} \mathrm{~mol}^{-1}\right)$ is destabilised relative to 3.0.0_A (Figures 9d and 9e respectively). Thus, H-bonding between urea molecules appears to be more highly structuring than $\mathrm{Cl} \cdots$ urea $\mathrm{H}$-bonding interactions.
Table 5. Association energies $\left(E_{\mathrm{a}}\right)$ for the isolated reactants, and association energies $\left(\Delta E_{\mathrm{a}}\right)$ for the successive addition of urea molecules. Urea entering the $1^{\text {st }}$ coordination shell of chloride. Analogous quantities in terms of Gibbs free energies.

\begin{tabular}{ccccc}
\hline $\begin{array}{c}\text { Urea-Chloride } \\
\text { complex }\end{array}$ & $\begin{array}{c}\boldsymbol{E}_{\mathbf{a}} \\
\mathbf{k J ~ m o l}^{-1}\end{array}$ & $\begin{array}{c}\boldsymbol{\Delta} \boldsymbol{E}_{\mathbf{a}} \\
\mathbf{k J ~ m o l}^{\mathbf{1}}\end{array}$ & $\begin{array}{c}\boldsymbol{G}_{\mathbf{a}} \\
\mathbf{k J ~ m o l}^{-1}\end{array}$ & $\begin{array}{c}\boldsymbol{\Delta} \boldsymbol{G}_{\mathbf{a}} \\
\mathbf{k J} \mathbf{~ m o l}^{-\mathbf{1}}\end{array}$ \\
\hline$\left[\mathrm{Cl}(\text { urea }]^{-}\left(1.0 .0 \_\mathrm{A}\right)\right.$ & -106 & -106 & -120 & -120 \\
{$\left[\mathrm{Cl}(\text { urea) }]_{2}\right]^{-}\left(2.0 .0 \_\mathrm{A}\right)$} & -191 & -85 & -178 & -59 \\
{$\left[\mathrm{Cl}(\text { urea) })_{3}\right]^{-}\left(3.0 .0 \_\mathrm{A}\right)$} & -260 & -69 & -212 & -33 \\
\hline
\end{tabular}

40 Table 6. Association energies $E_{\mathrm{a}}$ in $\mathrm{kJ} \mathrm{mol}^{-1}$ of the three lowest energy urea-chloride clusters (employing B3LYP-D2/ 6-311++G(d,p) structures)

\begin{tabular}{rccc}
\hline Urea-Chloride complex & $\begin{array}{c}\text { B3LYP-D2 } \\
\text { 6-311++G(d,p) aug-cc-pVTZ aug-cc-pVDZ }\end{array}$ & $\begin{array}{c}\text { MP2 } \\
\text { CCSD(T) }\end{array}$ & -116 \\
\hline$[\mathrm{Cl}(\text { urea })]^{-}\left(1.0 .0 \_\mathrm{A}\right)$ & -109 & -112 & -209 \\
{$\left[\mathrm{Cl}(\text { urea })_{2}\right]^{-}\left(2.0 .0 \_\mathrm{A}\right)$} & -197 & -200 & -197 \\
{$\left[\mathrm{Cl}(\text { urea)•urea }]^{-}\left(1.1 .0 \_\mathrm{A}\right)\right.$} & -189 & -188 & - \\
{$\left[\mathrm{Cl}(\text { urea })_{3}\right]^{-}\left(3.0 .0 \_\mathrm{A}\right)$} & -269 & -271 & - \\
\hline
\end{tabular}

Association energies $E_{\mathrm{a}}=E$ (cluster) $(n E$ (urea $)+E$ (chloride) $)$, and $\Delta E_{\mathrm{a}}$ for the addition of successive urea molecules to the first ${ }_{45}$ coordination shell of $\mathrm{Cl}^{-}\left(\left[\mathrm{Cl}(\text { urea })_{\mathrm{n}}\right]^{-}+\right.$urea $\left.\rightarrow\left[\mathrm{Cl}(\text { urea })_{\mathrm{n}+1}\right]^{-}\right)$ are given in Table 5, as are $G_{\mathrm{a}}$ and $\Delta G_{\mathrm{a}}$. $E_{\mathrm{a}}$ of key low energy clusters computed employing B3LYP-D2/6-311++G(d,p) geometries at the MP2 and $\operatorname{CCSD}(\mathrm{T})$ levels are presented in Table 6 and indicate that the B3LYP-D2/6-311++G(d,p) method 50 is recovering energy differences to a good level of accuracy. Unfortunately, the $\operatorname{CCSD}(\mathrm{T})$ calculation for $\left[\mathrm{Cl}(\text { urea })_{3}\right]^{-}$was beyond our resources. There are slight differences between the B3LYP-D2/6-311++G(d,p) values in Table 5 and Table 6 because those in the former are ZPE and BSSE corrected while 55 those in the latter are only BSSE corrected to allow comparison with the MP2 results.

Concomitant with the decrease in values of $\Delta E_{\mathrm{a}}$ as additional urea molecules are added (Table 5) is a decrease in the average strength of the $\mathrm{NH} \cdots \mathrm{Cl} \mathrm{H}$-bonds. The average length of the ${ }_{60} \mathrm{NH} \cdots \mathrm{Cl}$ interaction increases from $2.32 \AA\left(1.0 .0 \_\mathrm{A}\right)$ to $2.38 \AA$ (2.0.0_A) to $2.44 \AA$ (3.0.0_A) and the average value of $\rho_{\mathrm{BCP}}$ decreases from 0.020 au to 0.018 au to 0.015 au respectively. Full details of the individual H-bond analysis for all the clusters can be found in the ESI, Table S12.

65 The $\mathrm{NH} \cdots \mathrm{Cl}$ interactions are highly flexible in terms of strength and span from weak to moderate, depending on the local environment. For example, $\rho_{\mathrm{BCP}}$ spans $0.012-0.028$ au and the corresponding $E^{(2)}$ values range from $15-73 \mathrm{~kJ} \mathrm{~mol}^{-1}$. However, the average value of $\rho_{\mathrm{BCP}}$ for the $\mathrm{NH} \cdots \mathrm{Cl} \mathrm{H}$-bonds in [Cl(urea $\left.)_{2}\right]^{-}$, $702.0 .0 \_\mathrm{A}$, is $(0.018 \mathrm{au})$ and thus is similar to the average $\rho_{\mathrm{BCP}}$ for the $\mathrm{CH} \cdots \mathrm{Cl} \mathrm{H}$-bonds in $\mathrm{ChCl}(0.018$ au, sampled over all the $\mathrm{ChCl}$ ion-pairs), despite $\mathrm{NH}$ typically being thought of as the better H-bond donor. Thus, we again find that the doubly ionic $\mathrm{H}$-bond of a traditionally weaker donor, can be competitive with 75 the ionic H-bond of a stronger donor. Furthermore, as $E^{(2)}$ and $\rho_{\mathrm{BCP}}$ are measures of the covalent contribution to the H-bond interaction, the doubly ionic $\mathrm{CH}^{\cdots} \mathrm{Cl}^{-}$interaction is, on average, as covalent as the anionic $\mathrm{NH} \cdots \mathrm{Cl}^{-}$interaction. 


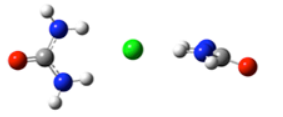

(a) $2.0 .0 \mathrm{~A}$

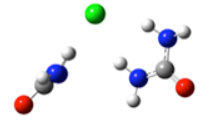

(b) $2.0 .0 \mathrm{~B}$

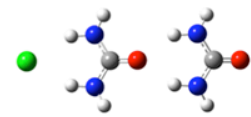

(c) 1.1.0_A

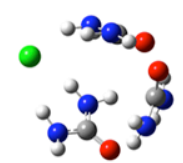

$(0.0 / \overline{16.2)}$

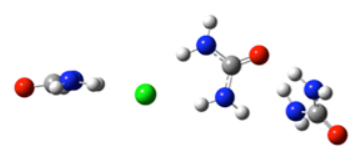

(f) $\begin{gathered}2.1 .0-B \\ (11.4 / 2.1)\end{gathered}$ (d) $\quad 2.1 .0 \mathrm{~A}$
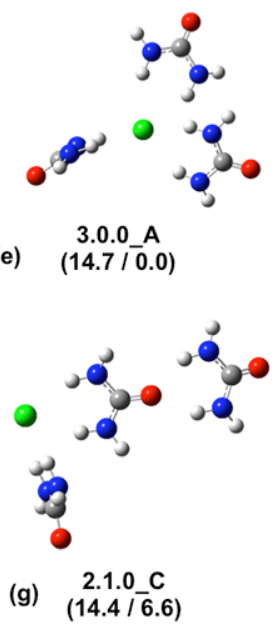

Figure 9. Selected $\left[\mathrm{Cl}(\text { urea })_{n}\right]^{-} \mathrm{n}=2,3$ structures conformer energy relative to the lowest energy structure $(\Delta \mathrm{E} / \Delta \mathrm{G})$ in $\mathrm{kJ} \mathrm{mol}^{-1}$.

Analysis of the H-bonding MOs reveals there to be limited 5 orbital overlap between the $\mathrm{Cl}^{-}$and urea fragments, reflective of a closed shell type interaction, ESI Figure S10. Cluster 2.1.0_A has the largest number of $\mathrm{H}$-bond interactions found here for a 3:1 composition (ten H-bonds: $4 \times \mathrm{NH} \cdots \mathrm{Cl}, 4 \times \mathrm{NH} \cdots \mathrm{O}=\mathrm{C}$ and 2 $\left.\mathrm{x} N \mathrm{NH}^{-\cdots}\right)$. The sum of $\rho_{\mathrm{BCP}}$ can be used as a measure of the 10 overall level of $\mathrm{H}$-bonding. Within 2.1.0_A the sum of $\rho_{\mathrm{BCP}}$ equates to $0.167 \mathrm{au}$, the third largest value for the 3 urea:chloride complexes. The sum of $\rho_{\mathrm{BCP}}$ is higher for both 1.2.0_A (0.171 au, 9 H-bonds) and 1.1.1_C (0.175 au, 6 H-bonds), despite forming fewer H-bonds. H-bonding is therefore not maximised despite 15 2.1.0_A having the largest number of H-bonds.

\section{The $\left[\mathrm{Cl}(\text { urea })_{2}\right]^{-}$cluster}

In terms of the eutectic formed at the 1:2 molar ratio of [choline]Cl:urea, we are interested in the energy and structural form of the $\left[\mathrm{Cl}(\text { urea })_{2}\right]^{-}$cluster.

20 The association energies presented in Table 5 show that addition of urea molecules up to the 1:3 ratio will favour the formation of $\left[\mathrm{Cl}(\text { urea })_{3}\right]^{-}$. However, while the addition of a urea molecule to $\left[\mathrm{Cl}(\text { urea })_{2}\right]^{-}$is stabilising, addition of urea to another urea molecule (forming a dimer), is only another $\Delta E_{\mathrm{a}}=10$ or ${ }_{25} \Delta G_{\mathrm{a}}=16 \mathrm{~kJ} \mathrm{~mol}^{-1}$ higher in energy. Moreover, in terms of energy cost, addition of a third urea molecule into a second solvation shell (2.1.0_A, 2.1.0_B and 2.1.0_C, Figures 9d, 9f and 9g respectively) is similar to placing all three urea molecules in the first solvation shell (3.0.0_A, Figure 9e), $\Delta E$ and $\Delta G$ for these 30 conformers range over $15 \mathrm{~kJ} \mathrm{~mol}^{-1}$ (energies favour 2.1.0_A while Gibbs free energies favour 3.0.0). Thus, internally, stronger H-bonding favours 2.1.0_A while including molecular entropy effects make 3.0.0. competitive. Nevertheless, there are more potential 2.1.0 conformers and urea-urea associations are 35 competitive with the addition of urea to $\left[\mathrm{Cl}(\text { urea })_{2}\right]^{-}$. Overall, there are indications that formation of $\left[\mathrm{Cl}(\mathrm{urea})_{2}\right]^{-}$is likely.
Intuitively a symmetric delocalised cluster such as $2.0 .0 \_\mathrm{A}$ is proposed for $\left[\mathrm{Cl}(\text { urea })_{2}\right]^{-}$(Figure 9a). However, $\left[\mathrm{Cl}(\text { urea })_{2}\right]^{-}$is equally stable with both urea molecules collected on one "side" 40 of $\mathrm{Cl}^{-}$(2.0.0_B, Figure 9b). In 2.1.0_A (Figure 9d) the three urea molecules form a $\mathrm{H}$-bonded ring on one side of $\mathrm{Cl}^{-}$. Chloride has been shown to polarise within bulk water, the waters of hydration preferentially "grouping" on one side of chloride. ${ }^{\mathbf{2}}$ The formation of a dipole moment, the relative polarisability of ${ }_{45} \mathrm{Cl}^{-}$, entropy effects and water-water $\mathrm{H}$-bonding, have been identified as factors potentially contributing to the anisotropic cluster formation. ${ }^{\mathbf{2}}$ Similar effects may be present here. Nevertheless, 2.1.0_B $\left(\Delta G=2.1 \mathrm{~kJ} \mathrm{~mol}^{-1}\right.$, Figure 9f) in particular, exhibits the anticipated symmetric solvation pattern of a solvated ${ }_{50}\left[\mathrm{Cl}(\text { urea })_{2}\right]^{-}$conformer. Both 2.1.0_B and 2.1.0_C (Figure 9g) show strong urea-urea interactions. Thus, while a symmetric solvation structure for $\left[\mathrm{Cl}(\text { urea })_{2}\right]^{-}$is evident, other less symmetrical conformers are competitive.

Should these systems be considered as clusters formed of ${ }_{55}$ neutral urea molecules H-bonding with an anion; urea $\bullet[\mathrm{Cl}]^{-}$and 2urea $[\mathrm{Cl}]^{-}$(where square brackets enclose the negatively charged species) or should they be considered as complexes with the negative charge delocalised over the entire cluster such as $[\mathrm{Cl} \text { (urea) }]^{-}$and $\left[\mathrm{Cl}(\text { urea })_{2}\right]^{-}$?

60 The degree of charge transfer on chloride-urea association is presented in Table 4. Charge is transferred from chloride to urea, and the average of the (NBO) charge transfer for the clusters under $15 \mathrm{~kJ} \mathrm{~mol}^{-1}$ increases with the number of coordinated urea molecules; 1urea: $\mathrm{Cl}^{-}(0.076 e)$, 2urea: $\mathrm{Cl}^{-}(0.101 e)$ and 3urea: $\mathrm{Cl}^{-}$ ${ }_{65}(0.108 e)$. For comparison, the equivalent average for cholinechloride ion pairs is $0.126 e$. Thus, the charge transfer within $\left[\mathrm{Cl}(\text { urea })_{3}\right]^{-}$is $\approx 86 \%$ of that between the choline and chloride ions. Similarly to the ion-pair, the complex MOs show limited delocalisation. Thus, if the ion-pair is not considered to be 70 strongly delocalised, then neither is the charge in these clusters. Thus rather than referring to the structures as delocalised $\left[\mathrm{Cl}(\text { urea })_{\mathrm{n}}\right]^{-}$complexes we will identify these as $n$ urea $\cdot[\mathrm{Cl}]^{-}$ clusters.

The key results of this section are that urea associates strongly 75 with $\mathrm{Cl}^{-}$, however urea-urea interactions are competitive with the addition of a third urea molecule to $2 \mathrm{urea} \cdot[\mathrm{Cl}]^{-}$. Moreover, 2urea $[\mathrm{Cl}]^{-}$is not necessarily a symmetrically solvated cluster. Analysis of the $2 \mathrm{urea} \cdot[\mathrm{Cl}]^{-}$charge distribution indicates that the negative charge is not strongly delocalised over the whole first 80 solvation shell but remains localised on $\mathrm{Cl}^{-}$.

\section{Choline-Urea Pairs}

For the $\mathrm{ChCl}$ - urea eutectic, the focus has typically been on the urea-chloride interaction. However, we have found the ureacholine interaction to also be important, in addition this ${ }_{85}$ interaction is an exemplar for cationic H-bonds. Choline-urea pairs were obtained in an analogous manner to the cholinechloride ion pairs, structures are presented in Figure $\mathbf{1 0}$ and relative energies provided in Table 7 (further details in the ESI, Table 13). 


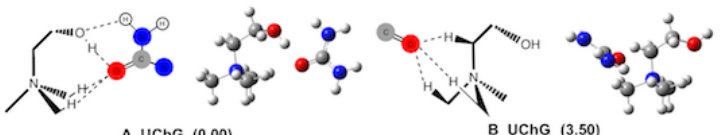

A_UChG $(0.00)$
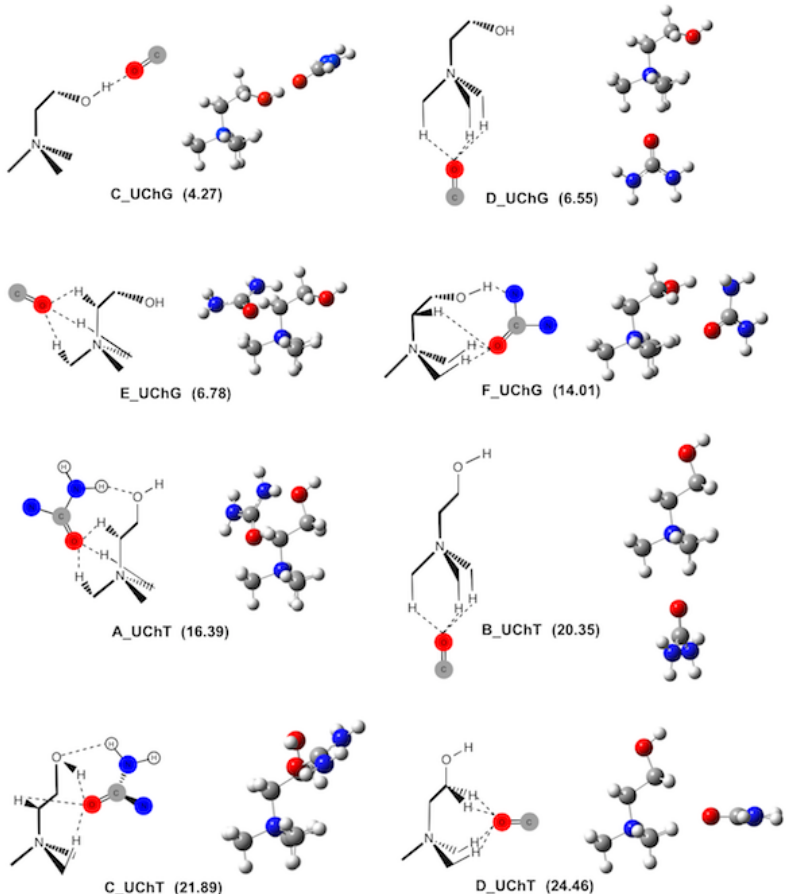

Figure 10. Choline-Urea pairs, the urea molecule is truncated in some representations for clarity, relative energy in $\mathrm{kJ} \mathrm{mol}^{-1}$.

Five conformers lie within $10 \mathrm{~kJ} \mathrm{~mol}^{-1}$ of the lowest energy 5 structure (A_UChG), demonstrating flexibility in the choline-urea associations and potential for significant entropic contributions. The spread in the relative energies of the choline-urea pairs $(\approx 25$ $\left.\mathrm{kJ} \mathrm{mol}^{-1}\right)$ is of the same order of magnitude as the range found for the choline-chloride ion pairs $\left(\approx 38 \mathrm{~kJ} \mathrm{~mol}^{-1}\right)$.

10 The association energy of the lowest energy choline-urea conformer A_UChG is $-82 \mathrm{~kJ} \mathrm{~mol}^{-1}$. The $E_{\mathrm{a}}$ computed using B3LYP-D2/6-311++G(d,p) geometries at the B3LYP-D2/6$311++\mathrm{G}(\mathrm{d}, \mathrm{p})$ (BSSE corrected), MP2/aug-cc-pVTZ (BSSE corrected) and $\mathrm{CCSD}(\mathrm{T}) /$ aug-cc-pVDZ levels is $-86,-77,-87 \mathrm{~kJ}$ $15 \mathrm{~mol}^{-1}$, respectively, while the B_UChG conformer lies 6,2 and 5 $\mathrm{kJ} \mathrm{mol}^{-1}$ higher in energy, respectively. The four lowest energy conformers all have $\Delta G_{\mathrm{a}}$ within $2 \mathrm{~kJ} \mathrm{~mol}^{-1}$, and $G_{\mathrm{a}}=-44 \mathrm{~kJ} \mathrm{~mol}^{-1}$ for the most stable conformer, C_UChG. Thus, we again find that $\mathrm{H}$-bonding imposes constraints that impact on entropic 20 contributions.

The $E_{\mathrm{a}}$ for choline-urea is therefore $24 \mathrm{~kJ} \mathrm{~mol}^{-1}$ less than for chloride-urea, but, almost equal to the association energy of a second urea molecule to chloride $\left(-85 \mathrm{~kJ} \mathrm{~mol}^{-1}\right)$. Moreover, the choline-urea association energy is greater than the urea-urea 25 association energy $\left(-59 \mathrm{~kJ} \mathrm{~mol}^{-1}\right)$. Thus, choline-urea interactions are competitive with the coordination of a second urea to urea $\cdot[\mathrm{Cl}]^{-}$and with urea-urea interactions. Based on pairwise association energies, we may expect to see choline-urea interactions featuring prominently. Thus, this result has 30 implications for the formation of $2 \mathrm{urea}[\mathrm{Cl}]^{-}$, the key species assumed to form at the 1:2 eutectic point. Rather than a "charge diffuse" 2 urea $[\mathrm{Cl}] \cdot[\mathrm{Ch}]$ cluster forming, a "novel" urea $[\mathrm{Cl}] \cdot u r e a[\mathrm{Ch}]$ cluster may be important.
Table 7. Relative energies and charge transfer (CT) for the choline-urea 35 pairs

\begin{tabular}{cccc}
\hline Choline-Urea Pair & $\boldsymbol{\Delta} \boldsymbol{E}_{\text {rel }} / \mathbf{~ k J ~ m o l}^{-1}$ & $\mathbf{C T}$ (NBO) $/ \boldsymbol{e}$ & $\mathbf{C T}$ (CHELPG) /e \\
\hline A_UChG & 0.00 & 0.066 & 0.074 \\
B_UChG & 3.50 & 0.019 & 0.081 \\
C_UChG & 4.27 & 0.060 & 0.067 \\
D_UChG & 6.55 & 0.020 & 0.089 \\
E_UChG & 6.78 & 0.020 & 0.049 \\
F_UChG & 14.01 & 0.030 & 0.071 \\
A_UChT & 16.39 & 0.019 & 0.080 \\
B_UChT & 20.35 & 0.021 & 0.083 \\
C_UChT & 21.89 & 0.033 & 0.075 \\
D_UChT & 24.46 & 0.020 & 0.047 \\
\hline
\end{tabular}

\section{H-bonding interactions}

The majority of the choline-urea interactions involve urea acting as a H-bond acceptor through the oxygen of the carbonyl 40 group. The $\delta^{-}$oxygen atom, positions at the approximate centre of the tetrahedral faces of the choline cation. Similar to $\mathrm{ChCl}$, the lowest energy choline-urea conformer (A_UChG) has urea forming a H-bond with the $\mathrm{OH}$ functionality; (choline) $\mathrm{OH} \cdots \mathrm{O}=\mathrm{C}($ urea). The $\mathrm{OH} \cdots \mathrm{O}=\mathrm{C} \mathrm{H}$-bond is one of the 45 strongest formed in this system (mean $\rho_{\mathrm{BCP}}=0.044 \mathrm{au}$ ). Based on the QTAIM criteria, the $\mathrm{OH} \cdots \mathrm{O}=\mathrm{C} \mathrm{H}$-bonds within A_UChG and C_UChG fall within the moderate $\mathrm{H}$-bond range. This is consistent with the $E^{(2)}$ sum of the stabilisation energies for $n_{\mathrm{O}} \rightarrow$ $\sigma_{\mathrm{O}-\mathrm{H}} *$ interactions within $\mathrm{A} \_\mathrm{UChG}$ and $\mathrm{C} \_\mathrm{UChG}$ which are $\approx$ 50114 and $125 \mathrm{~kJ} \mathrm{~mol}^{-1}$ respectively, and are amongst the largest values computed here for a single $\mathrm{H}$-bond. A conformer exhibiting a linear $\mathrm{OH} \cdots \mathrm{O}=\mathrm{C}$ interaction (i.e. no $\mathrm{CH} \cdots \mathrm{X}$ interactions) has also been obtained $\left(\mathrm{C}_{-} \mathrm{UChG}\right)$. This is in contrast to $\mathrm{ChCl}$ where an analogous structure was investigated ${ }_{55}$ but found to be unstable.

In contrast, the (choline) $\mathrm{CH} \cdots \mathrm{O}=\mathrm{C} \mathrm{H}$-bonds are the weakest type of primary $\mathrm{H}$-bond considered here, with an average $\rho_{\mathrm{BCP}}$ value $(0.013 \mathrm{au})$ below that for the intramolecular $\mathrm{CH} \cdots \mathrm{OH} \mathrm{H}$ bond in choline. The nitrogen of urea is also capable of acting as 60 a H-bond acceptor, forming a (choline) $\mathrm{OH} \cdots \mathrm{NH}$ (urea) H-bond (F_UChG). Full details of the choline-urea H-bonding analysis can be found in the ESI, Table S14.

Urea is capable of acting as a H-bond donor and a number of conformers are found where urea is the donor and choline is the 65 acceptor, such as in the (choline)HO $\cdots \mathrm{HN}$ (urea) H-bond. A similar interaction has also been observed in MD simulations, where it is reported to be the least frequently formed interaction with the $\mathrm{OH}$ group of choline. ${ }^{27}$

\section{Ionic-interactions}

70 Charge transfer for the $\mathrm{NBO}$ and CHELPG methods are reported in Table 7. When urea is acting as a H-bond acceptor there is net charge transfer from urea to choline. The positive charge on urea varies from $+0.019 e$ to a maximum of $+0.066 e$ (NBO), the average charge transfer for conformers under $15 \mathrm{~kJ}$ $75 \mathrm{~mol}^{-1}$ is $0.036 \mathrm{e}$ (Table 7). Thus, the magnitude of charge transfer for the lowest energy conformers of urea $[\mathrm{Ch}]^{+}(0.066 e)$, where urea is the donor, is of a similar size to that for urea[Cl] $]^{-}(0.076 e)$ where urea is the acceptor. 
Accounting for the effects of charge transfer is important, particularly for accurate MD simulations. Ionic liquid ions can be modelled employing a reduced charge to account for the ionpair charge transfer; a practice now routinely applied in the MD 5 simulation of ILs. The (NBO) charge transfer computed here for $\mathrm{ChCl}$ is $\approx 0.13 e$. In setting up a simulation the charges on the ions may be reduced slightly from \pm 1 to model this effect. When a urea molecule is paired with choline it becomes positively charged, and when paired with chloride it becomes negatively

10 charged. Treating urea as a neutral molecule may balance these two effects and better recover the charge neutral urea-urea interactions. However, urea would ideally be represented as a species able to both accrue and loose a small amount of charge, the amount being highly dependent on the local environment.

15 The (NBO) charge on choline in the lowest energy conformer of urea $[\mathrm{Ch}]^{+}$is $+0.934 e$. To evaluate which has the stronger Coulomb contributions, the proposed "charge diffuse" 2 urea $[\mathrm{Cl}] \bullet[\mathrm{Ch}]$ cluster or the "novel" urea $[\mathrm{Cl}] \bullet$ urea $[\mathrm{Ch}]$ cluster, we can assume that the charge centres are separated by the same ${ }_{20}$ distance and evaluate the product of the charges. The charge on chloride in 2 urea $[\mathrm{Cl}]^{-}$is $-0.924 e$ and combined with $+1.0 \mathrm{e}$ for choline, the product is $0.903 e^{2}$ for $2 \mathrm{urea}[\mathrm{Cl}] \cdot[\mathrm{Ch}]$. In contrast, the charge on chloride in urea $[\mathrm{Cl}]^{-}$is $-0.903 e$ and the charge on urea $[\mathrm{Ch}]^{+}$is $0.934 \mathrm{e}$, thus the product for urea[Cl]*urea[Ch] is 25 significantly less, $0.863 e^{2}$. The corresponding CHELPG products are $0.864 e^{2}$ and $0.825 e^{2}$ respectively. Both methods show a reduction in charge of $0.04 e^{2}$ on moving from $2 \mathrm{urea}[\mathrm{Cl}] \cdot[\mathrm{Ch}]$ to the urea[Cl]•urea[Ch] system. Thus, in both cases the urea $[\mathrm{Cl}] \cdot$ urea[Ch] cluster has a reduced charge and could be 30 considered more "charge diffuse". Urea, upon addition to $\mathrm{ChCl}$, could act as a "disruptor" to the regular $\mathrm{ChCl}$ packing, as a "spacer", separating ions and reducing interactions, and as an "attenuator", dispersing the charge over a complex.

The key results of this section are the identification of the 35 choline-urea $\mathrm{OH} \cdots \mathrm{O}=\mathrm{C} \mathrm{H}$-bond as the strongest among the $\mathrm{H}-$ bonds studied here. The strength of the Ch-urea interaction is significant, and competitive with the formation of $2 \mathrm{urea} \cdot[\mathrm{Cl}]^{-}$ moreover urea $[\mathrm{Cl}] \cdot$ urea $[\mathrm{Ch}]$ is more charge diffuse than $2 \mathrm{urea}[\mathrm{Cl}] \cdot[\mathrm{Ch}]$, these results indicate that the 2 urea $\bullet[\mathrm{Cl}]^{-}$ 40 complex may not dominate in 1:2 eutectic mixtures. Urea can act equally well as a H-bond donor with choline or $\mathrm{H}$-bond acceptor with $\mathrm{Cl}^{-}$. Charge transfer can occur to or from the urea, thus urea can act as a reservoir of electron density, donating or accepting small amounts of charge as required.

\section{${ }_{45}$ Comparing across Pairwise Interactions}

Examining the pairwise interactions of choline, chloride and urea has highlighted the wide range of interactions that can occur within a eutectic mixture, in this section we compare the different pairwise interactions. A summary of the maximum association ${ }_{50}$ energies $\left(E_{\mathrm{a}}\right)$ is provided in Table 8. The maximum interaction energy decreases as: choline-chloride $>>$ chloride-urea $>$ cholineurea $>$ urea-urea. This is consistent with the decrease in Coulomb derived interactions from ion-ion to ion-dipole to dipole-dipole as identified in Table 8. The very large association energy of the ${ }_{55} \mathrm{ChCl}$ ion pairs reflects the dominant Coulombic attraction between the two oppositely charged ions in the gas phase. The dipole moment of urea is quite large and this, combined with the moderate H-bonding, can explain the sizeable association energies for the pairs featuring urea.

60 Table 8. Maximum B3LYP-D2/6-311++G(d,p) association energies, $E_{\mathrm{a}}$, (ZPE and BSSE corrected) and the corresponding single point MP2

association energies (BSSE corrected) and Gibbs free association energies $G_{\mathrm{a}}$ in $\mathrm{kJ} \mathrm{mol}^{-1}$, for pairwise interactions. $n \mathrm{U}$ refers to the number of urea molecules in the $1^{\text {st }}$ coordination sphere of chloride.

\begin{tabular}{ccccc}
\hline Interaction & & $\begin{array}{c}E_{\mathrm{a}} \\
\mathrm{kJ} \mathrm{mol}^{-1}\end{array}$ & $\begin{array}{c}\mathrm{MP2} E_{\mathrm{a}} \\
\mathrm{kJ} \mathrm{mol}^{-1}\end{array}$ & $\begin{array}{c}G_{\mathrm{a}} \\
\mathrm{kJ} \mathrm{mol}^{-1}\end{array}$ \\
\hline $\begin{array}{c}\text { Choline- } \\
\text { Chloride }\end{array}$ & ion $(+) \cdots$ ion $(-)$ & -409 & -419 & -419 \\
$\begin{array}{c}\text { Urea- } \\
\text { Chloride }\end{array}$ & dipole $\left(\delta^{+}\right) \cdots$ ion $(-)$ & $-106(1 \mathrm{U})$ & $-112(1 \mathrm{U})$ & $-120(1 \mathrm{U})$ \\
$\begin{array}{c}\text { Urea- } \\
\text { Choline } \\
\text { Urea- } \\
\text { Urea }\end{array}$ & dipole $\left(\delta^{-}\right) \cdots$ ion $(+)$ & $-69(3 \mathrm{U})$ & $-88(2 \mathrm{U})$ & $-59(2 \mathrm{U})$ \\
& dipole $\left(\delta^{+}\right) \cdots$ dipole $\left(\delta^{-}\right)$ & -82 & -77 & $-33(3 \mathrm{U})$ \\
& & -56 & -17 \\
\hline
\end{tabular}

The $E_{\mathrm{a}}$ values for chloride-urea decrease for successive addition of urea to the $1^{\text {st }}$ coordination shell of chloride. The $E_{\mathrm{a}}$ of urea $[\mathrm{Cl}]^{-}$with a second urea molecule is close to the $E_{\mathrm{a}}$ of choline with a urea molecule forming urea $[\mathrm{Ch}]^{+}$clusters. Moreover, the 70 urea-urea $E_{\mathrm{a}}$ approaches that of $3 \mathrm{urea}[\mathrm{Cl}]^{-}$. These interactions all lie within $15 \mathrm{~kJ} \mathrm{~mol}^{-1}$ of each other, and indicate that the $n$ urea $[\mathrm{Cl}]^{-}$associations, $\mathrm{n}=2,3$, are competing with both cholineurea and urea-urea interactions. Thus, while urea $[\mathrm{Cl}]^{-}$is favoured, the formation of a $2 \mathrm{urea}[\mathrm{Cl}]^{-}$cluster is not necessarily 75 dominant.

The energy of formation is not the only key factor, the range of accessible low energy structures will effect the solution entropy. $\mathrm{ChCl}$ has two structures within $10 \mathrm{~kJ} \mathrm{~mol}^{-1}$ of the lowest energy structure, both urea $[\mathrm{Cl}]^{-}$and 3 urea $[\mathrm{Cl}]^{-}$have only one structure, 80 urea $[\mathrm{Cl}]^{-}$has three low energy conformers, while in contrast urea $[\mathrm{Ch}]^{+}$has five low energy conformers. Thus, the range of potential urea $[\mathrm{Ch}]^{+}$structures may also act to increase the entropy of the system. Overall, the large range of low energy structures, will lead to a flexible and dynamic system.

\section{${ }_{85}$ Comparing Across the Range of $\mathbf{H}$-bonding Interactions}

Examining the individual interactions of choline, chloride and urea has shown that there is an exceptionally wide range of $\mathrm{H}$ bonding possible within the ChCl-urea mixture. We now compare and contrast these different types of H-bonding. Mean 90 values and the range of $\rho_{\mathrm{BCP}}, \mathrm{H}$-bond length, $r$, and $E^{(2)}$ for each dimer type and the $n$ urea[Cl $]^{-}$( $\mathrm{n}=1,2$ or 3 ) clusters are detailed in Table 9. The mean $\rho_{\mathrm{BCP}}$ is the average of the values of $\rho_{\mathrm{BCP}}$ for all $\mathrm{H}$-bonds of a given type e.g. mean $\rho_{\mathrm{BCP}}$ for all $\mathrm{NH} \cdots \mathrm{O}=\mathrm{C} \mathrm{H}-$ bonds includes all those identified, in both the urea-dimers and 95 urea-chloride complexes. In an analogous manner the $E^{(2)}$ values have also been presented.

A large number of different H-bond types have been found, spanning from very weak to moderately-strong. Table 10 lists the H-bonds in descending order of mean $\rho_{\mathrm{BCP}}$. The precise 100 ordering should not be taken as definitive. For example, if arranged according to the maximum $\rho_{\mathrm{BCP}}$ value the ordering subtly changes. The $\mathrm{OH} \cdots \mathrm{O}=\mathrm{C}$ interaction is, by some margin, the strongest $\mathrm{H}$-bond observed here (upper moderate), followed by the $\mathrm{NH} \cdots \mathrm{O}=\mathrm{C}$ and $\mathrm{OH} \cdots \mathrm{Cl}$ interactions (lower moderate). ${ }_{105} \mathrm{Next}$ are the $\mathrm{NH} \cdots \mathrm{Cl}$ and $\mathrm{CH} \cdots \mathrm{Cl}$ interactions (upper weak) and finally the $\mathrm{CH} \cdots \mathrm{O}$ (intra.), $\mathrm{CH} \cdots \mathrm{O}=\mathrm{C}$ and $\mathrm{NH} \cdots \mathrm{N}$ H-bonds (lower 
weak).

For some H-bond types there is a large range of values dependent on the H-bonding motif. For example, $\rho_{\mathrm{BCP}}$ of the $5 \mathrm{NH} \cdots \mathrm{O}=\mathrm{C}$ interactions varies from 0.011 to 0.046 au i.e. from less than the mean value of $\rho_{\mathrm{BCP}}$ for the weak intramolecular $\mathrm{CH} \cdots \mathrm{O}(\mathrm{H}) \mathrm{H}$-bond in choline, to one of the stronger H-bonds found in this system. The corresponding ranges in H-bond lengths are $0.80 \AA$ and $E^{(2)}$ are $116 \mathrm{~kJ} \mathrm{~mol}^{-1}$.

10 Urea, in the solid state, forms a highly ordered H-bonded network, and $\mathrm{ChCl}$ is an ionic solid, thus relative to the isolated constituents there is undoubtedly an increase of disorder within the eutectic mixture. Most molecular liquids have a limited range of H-bonds, for example water has just one, the $\mathrm{HOH} \cdots \mathrm{OH}_{2} \mathrm{H}-$
15 bond. The introduction of many different and competitive $\mathrm{H}-$ bond types increases the number of accessible configurations within the mixture, and therefore the total entropy. There appears to be little energetic preference for the formation of fewer stronger H-bonds, or a larger number of weaker H-bonds. 20 Moreover, the observed flexibility in individual H-bond strength may allow the system to easily move from one state to another. Either H-bonding state (many weak or few strong H-bonds) could also result in greater structuring through H-bond networking. Thus, a more definitive rationalisation of the impact of a dynamic ${ }_{25}$ multitude of $\mathrm{H}$-bonds on the overall entropy of the real system is difficult to determine.

Table 9. Summary of selected H-bond properties for the different types of H-bond. XH = H-bond donor, $\mathrm{Y}=\mathrm{H}$-bond acceptor.

Choline Chloride Ion-Pairs

\begin{tabular}{|c|c|c|c|c|c|c|c|}
\hline $\begin{array}{l}\text { H-bond } \\
\mathrm{XH} \cdots \mathrm{Y}\end{array}$ & $\begin{array}{c}\text { Mean } \rho_{\mathrm{BCP}} / \\
\text { a.u } \\
\end{array}$ & $\begin{array}{c}\text { Range } \rho_{\mathrm{BCP}} / \\
\text { a.u } \\
\end{array}$ & $\begin{array}{c}\text { Mean r XH } \cdots \mathrm{Y} / \\
\AA \\
\end{array}$ & $\begin{array}{c}\text { Range r } \mathrm{XH} \cdots \mathrm{Y} / \\
\AA\end{array}$ & $\begin{array}{c}\text { Donor-Acceptor } \\
\text { Interaction }\end{array}$ & $\begin{array}{c}\text { Mean } E^{(2)} / \\
\mathrm{kJ} \mathrm{mol}^{-1}\end{array}$ & $\begin{array}{c}\text { Range } E^{(2)} / \\
\mathrm{kJ} \mathrm{mol}^{-1}\end{array}$ \\
\hline $\mathrm{CH}^{\cdots} \cdots \mathrm{Cl}$ & 0.018 & $0.008-0.022$ & 2.46 & $2.31-2.90$ & $n_{\mathrm{Cl}} \rightarrow \sigma_{\mathrm{C}-\mathrm{H}} *$ & 29.28 & $1.55-47.95$ \\
\hline $\mathrm{OH}^{\cdots} \cdot \mathrm{Cl}$ & 0.024 & $0.013-0.034$ & 2.28 & $2.09-2.55$ & $n_{\mathrm{Cl}} \rightarrow \sigma_{\mathrm{O}-\mathrm{H}} *$ & 55.08 & $16.07-89.37$ \\
\hline $\mathrm{CH} \cdots \mathrm{OH}$ (intra.) & 0.014 & $0.011-0.015$ & 2.36 & $2.25-2.52$ & $n_{\mathrm{O}} \rightarrow \sigma_{\mathrm{C}-\mathrm{H}} *$ & 3.47 & $2.09-4.56$ \\
\hline \multicolumn{8}{|c|}{ Choline - Urea Pairs } \\
\hline $\begin{array}{l}\text { H-bond } \\
\text { XH } \cdots Y\end{array}$ & $\begin{array}{c}\text { Mean } \rho_{\mathrm{BCP}} / \\
\text { a.u }\end{array}$ & $\begin{array}{c}\text { Range } \rho_{\mathrm{BCP}} / \\
\text { a.u }\end{array}$ & 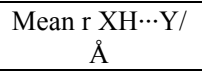 & $\begin{array}{c}\text { Range r XH } \cdots \mathrm{Y} / \\
\AA\end{array}$ & $\begin{array}{l}\text { Donor-Acceptor } \\
\text { Interaction }\end{array}$ & $\begin{array}{c}\text { Mean } E^{(2)} / \\
\mathrm{kJ} \mathrm{mol}^{-1}\end{array}$ & $\begin{array}{c}\text { Range } E^{(2)} / \\
\mathrm{kJ} \mathrm{mol}^{-1}\end{array}$ \\
\hline $\mathrm{CH} \cdots \mathrm{O}=\mathrm{C}$ & 0.013 & $0.008-0.024$ & 2.04 & $2.20-2.64$ & $\begin{array}{c}n_{\mathrm{O}} \rightarrow \sigma_{\mathrm{C}-\mathrm{H}}{ }^{*} \\
\pi_{\mathrm{C}=\mathrm{O}} \rightarrow \sigma_{\mathrm{C}-\mathrm{H}} *\end{array}$ & 7.91 & $0.46-25.65$ \\
\hline $\mathrm{OH} \cdots \mathrm{O}=\mathrm{C}$ & 0.044 & $0.032-0.050$ & 1.74 & $1.65-1.88$ & $\begin{array}{c}n_{\mathrm{O}} \rightarrow \sigma_{\mathrm{O}-\mathrm{H}^{*}} \\
\pi_{\mathrm{C}=\mathrm{O}} \rightarrow \sigma_{\mathrm{O}-\mathrm{H}}{ }^{*}\end{array}$ & 94.75 & $45.06-124.81$ \\
\hline $\mathrm{NH} \cdots \mathrm{OH}$ & 0.012 & $0.009-0.016$ & 2.34 & $2.14-2.48$ & $n_{\mathrm{O}} \rightarrow \sigma_{\mathrm{N}-\mathrm{H}} *$ & 9.69 & $3.72-19.71$ \\
\hline $\mathrm{OH} \cdots \mathrm{NH}$ & 0.019 & - & 2.17 & - & $n_{\mathrm{N}} \rightarrow \sigma_{\mathrm{O}-\mathrm{H}} *$ & 20.08 & - \\
\hline $\mathrm{CH} \cdots \mathrm{OH}$ (intra) & 0.015 & $0.012-0.018$ & 2.30 & $2.18-2.47$ & $n_{\mathrm{O}} \rightarrow \sigma_{\mathrm{C}-\mathrm{H}}{ }^{*}$ & 5.59 & $4.31-8.83$ \\
\hline \multicolumn{8}{|c|}{ Urea-Urea Dimers } \\
\hline 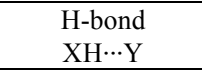 & $\begin{array}{c}\text { Mean } \rho_{\mathrm{BCP}} / \\
\text { a.u } \\
\end{array}$ & $\begin{array}{c}\text { Range } \rho_{\mathrm{BCP}} / \\
\text { a.u } \\
\end{array}$ & 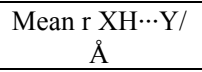 & $\begin{array}{c}\text { Range r XH } \cdots \mathrm{Y} / \\
\AA\end{array}$ & $\begin{array}{c}\text { Donor-Acceptor } \\
\text { Interaction }\end{array}$ & $\begin{array}{c}\text { Mean } E^{(2)} / \\
\mathrm{kJ} \mathrm{mol}^{-1}\end{array}$ & $\begin{array}{c}\text { Range } E^{(2)} / / \\
\mathrm{kJ} \mathrm{mol}^{-1}\end{array}$ \\
\hline $\mathrm{NH} \cdots \mathrm{O}=\mathrm{C}$ & 0.025 & $0.012-0.033$ & 2.01 & $1.83-2.40$ & $\begin{aligned} & n_{\mathrm{O}} \rightarrow \sigma_{\mathrm{N}-\mathrm{H}} * \\
& \pi_{\mathrm{C}=\mathrm{O}} \rightarrow \sigma_{\mathrm{N}-\mathrm{H}} *\end{aligned}$ & 42.18 & $4.52-68.91$ \\
\hline $\mathrm{NH} \cdots \mathrm{NH}$ & 0.023 & - & 2.09 & - & $n_{\mathrm{N}} \rightarrow \sigma_{\mathrm{N}-\mathrm{H}} *$ & 31.97 & - \\
\hline \multicolumn{8}{|c|}{ Urea-Chloride Complexes } \\
\hline $\begin{array}{l}\text { H-bond } \\
\mathrm{XH} \cdots \mathrm{Y}\end{array}$ & $\begin{array}{c}\text { Mean } \rho_{\mathrm{BCP}} / \\
\text { a.u } \\
\end{array}$ & $\begin{array}{c}\text { Range } \rho_{\mathrm{BCP}} / \\
\text { a.u } \\
\end{array}$ & $\begin{array}{c}\text { Mean r XH } \cdots \mathrm{Y} / \\
\AA \\
\end{array}$ & $\begin{array}{c}\text { Range } \mathrm{r} X \mathrm{XH} \cdots \mathrm{Y} / \\
\AA \\
\end{array}$ & $\begin{array}{c}\text { Donor-Acceptor } \\
\text { Interaction }\end{array}$ & $\begin{array}{c}\text { Mean } E^{(2)} / \\
\mathrm{kJ} \mathrm{mol}^{-1}\end{array}$ & $\begin{array}{c}\text { Range } E^{(2)} / \\
\mathrm{kJ} \mathrm{mol}^{-1}\end{array}$ \\
\hline $\mathrm{NH}^{\cdots} \cdot \mathrm{Cl}$ & 0.019 & $0.012-0.028$ & 2.36 & $2.18-2.59$ & $n_{\mathrm{Cl}} \rightarrow \sigma_{\mathrm{N}-\mathrm{H}} *$ & 36.79 & $14.77-72.97$ \\
\hline $\mathrm{NH} \cdots \mathrm{O}=\mathrm{C}$ & 0.027 & $0.011-0.046$ & 1.96 & $1.68-2.48$ & $\begin{array}{c}n_{\mathrm{O}} \rightarrow \sigma_{\mathrm{N}-\mathrm{H}}{ }^{*} \\
\pi_{\mathrm{C}=\mathrm{O}} \rightarrow \sigma_{\mathrm{N}-\mathrm{H}} *\end{array}$ & 44.69 & $2.38-118.16$ \\
\hline $\mathrm{NH} \cdots \mathrm{NH}$ & 0.010 & $0.006-0.017$ & 2.59 & $2.21-2.92$ & $n_{\mathrm{N}} \rightarrow \sigma_{\mathrm{N}-\mathrm{H}} *$ & 5.27 & $0.50-19.46$ \\
\hline
\end{tabular}

Table 10. The different types of H-bond observed, ordered according to the mean $\rho_{\mathrm{BCP}}$ values. Number (No.) of occurrences is the number of this type of $30 \mathrm{H}$-bond identified within the pairs of species isolated here. For the intramolecular $\mathrm{CH} \cdots \mathrm{O}$ H-bonds, $E^{(2)}$ values were not obtained in four cases.

\begin{tabular}{cccccccc}
\hline \multicolumn{2}{c}{ H-bond donor } & \multicolumn{2}{c}{ H-bond acceptor } & $\begin{array}{c}\text { Mean } \rho_{\mathrm{BCP}} / \mathrm{Mean}^{(2) /} \\
\mathrm{aJ} \mathrm{mol}\end{array}$ & $\begin{array}{c}\mathrm{Max} \rho_{\mathrm{BCP}} / \\
\mathrm{au}\end{array}$ & $\begin{array}{c}\text { No. of } \\
\text { occurrences }\end{array}$ \\
\hline $\mathrm{OH}$ & cation & $\mathrm{O}=\mathrm{C}$ & neutral & 0.044 & 94.75 & 0.050 & 3 \\
$\mathrm{NH}$ & neutral & $\mathrm{O}=\mathrm{C}$ & neutral & 0.026 & 44.44 & 0.046 & 41 \\
$\mathrm{OH}$ & cation & $\mathrm{Cl}$ & anion & 0.024 & 55.08 & 0.034 & 3 \\
$\mathrm{NH}$ & neutral & $\mathrm{Cl}$ & anion & 0.019 & 36.79 & 0.028 & 51 \\
$\mathrm{OH}$ & cation & $\mathrm{NH}$ & neutral & 0.019 & 20.08 & 0.019 & 1 \\
$\mathrm{CH}$ & cation & $\mathrm{Cl}$ & anion & 0.018 & 29.28 & 0.022 & 24 \\
$\mathrm{CH}$ & cation & $\mathrm{OH}$ & cation & 0.015 & 4.68 & 0.018 & 11 \\
$\mathrm{CH}$ & cation & $\mathrm{O}=\mathrm{C}$ & neutral & 0.013 & 7.91 & 0.024 & 26 \\
$\mathrm{NH}$ & neutral & $\mathrm{OH}$ & cation & 0.012 & 9.69 & 0.016 & 3 \\
$\mathrm{NH}$ & neutral & $\mathrm{NH}$ & neutral & 0.011 & 8.23 & 0.023 & 9 \\
\hline
\end{tabular}




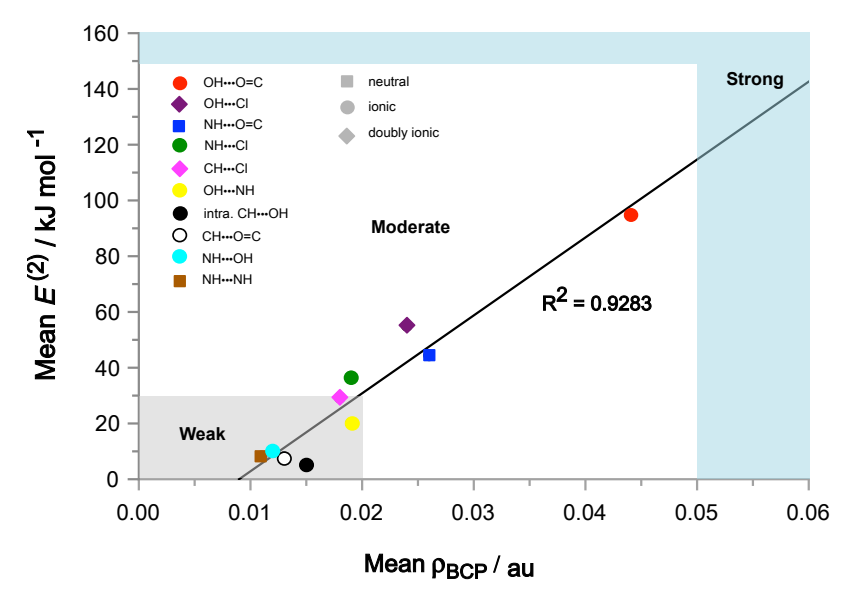

Figure 11. Plot of mean $E^{(2)}$ and mean $\rho_{\mathrm{BCP}}$ values for different H-bonds, data from Table 8 .

\section{Doubly Ionic H-bonds}

Doubly ionic H-bonds have become increasingly important with the development of ILs and DESs, however they are not well studied in comparison to traditional neutral and ionic H-bonds. 10 The very large range and type of H-bonds within the DES provides an opportunity for a direct comparison. It has been previously established that a relationship holds between $\rho_{\mathrm{BCP}}$ and $E^{(2)}$ for traditional neutral and ionic H-bonds. ${ }^{63,64}$ A plot of the mean $\rho_{\mathrm{BCP}}$ against mean $E^{(2)}$ values for the H-bonds examined

15 here, Figure 11, shows a reasonable correlation for neutral, ionic and doubly ionic H-bonds. The plot of $\rho_{\mathrm{BCP}}$ against $E^{(2)}$ for each of the 168 individual H-bonds, ESI, Figure S11 shows a "band" rather than a thin line, illustrating that for a given value of $\rho_{\mathrm{BCP}}$, there is some variation in $E^{(2)}$ (and vice versa).

20 The situation in a liquid environment will be complicated by the range of $\mathrm{H}$-bond motifs and the interdependence between the different $\mathrm{H}$-bonds e.g. if one $\mathrm{H}$-bond is strengthened, there can be a concomitant decrease in the strength of another. Rozas et al have previously shown there to be a correlation between the total 25 sum of the individual $\rho_{\mathrm{BCP}}$ and $E^{(2)}$ values, $\Sigma \rho_{\mathrm{BCP}}$ and $\Sigma E^{(2)}$, for H-bonded dimers with multiple intermolecular H-bonds. ${ }^{65}$ The correlation between $\Sigma \rho_{\mathrm{BCP}}$ and $\Sigma E^{(2)}$ for the systems studied here is shown in Figure 12. The correlations observed in Figures 11 and $\mathbf{1 2}$ indicate that trends found for the "doubly ionic" H-bonds $30 \mathrm{ILs} / \mathrm{DESs}$ are broadly consistent with those observed for normal H-bonds.

The association energy of two H-bonded species has frequently been used as an indicator of the strength of intermolecular H-bond(s), and a number of equations relating $E_{\mathrm{a}}$ ${ }_{35}$ to $\rho_{\mathrm{BCP}}$ have previously been derived for normal H-bonds. ${ }^{65}$ The relationship between $\Sigma \rho_{\mathrm{BCP}}$ and $E_{\mathrm{a}}$ was examined for all the complexes presented here, Figure 13. As expected, the strong ion-ion interactions dominate in choline-chloride and these are excluded from the fit (open circles, Figure 13). Nevertheless, the ${ }_{40}$ correlation obtained is poor. Trying to correlate $E_{\mathrm{a}}$ with $\Sigma \rho_{\mathrm{BCP}}$ across systems with different charges (i.e. neutral vs. ion-dipole vs. ion-ion) ignores the inherent differences in the electrostatic contribution to the association energy. This is most problematic for ion pairs, where the association energy is clearly dominated 45 by the Coulombic contribution.

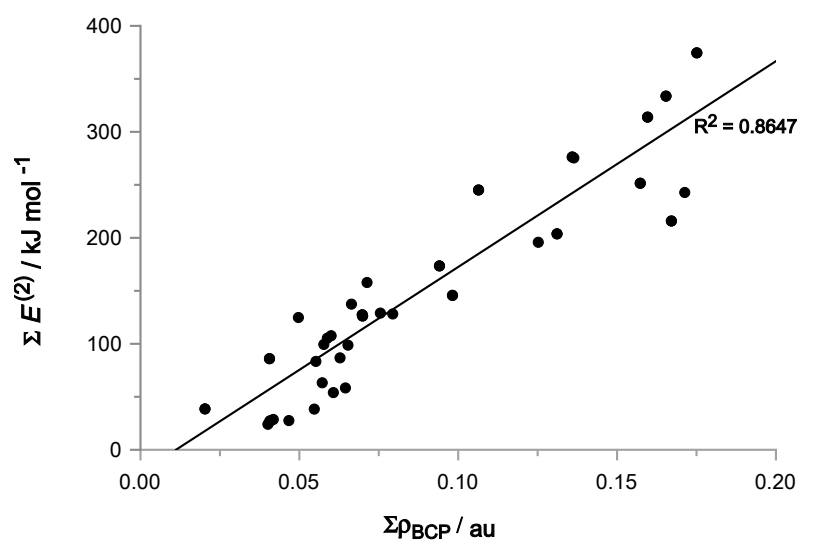

Figure 12. Plot of $\Sigma E^{(2)}$ and $\Sigma \rho_{\mathrm{BCP}}$ values for the intermolecular $\mathrm{H}$-bonds found in each of the complexes.

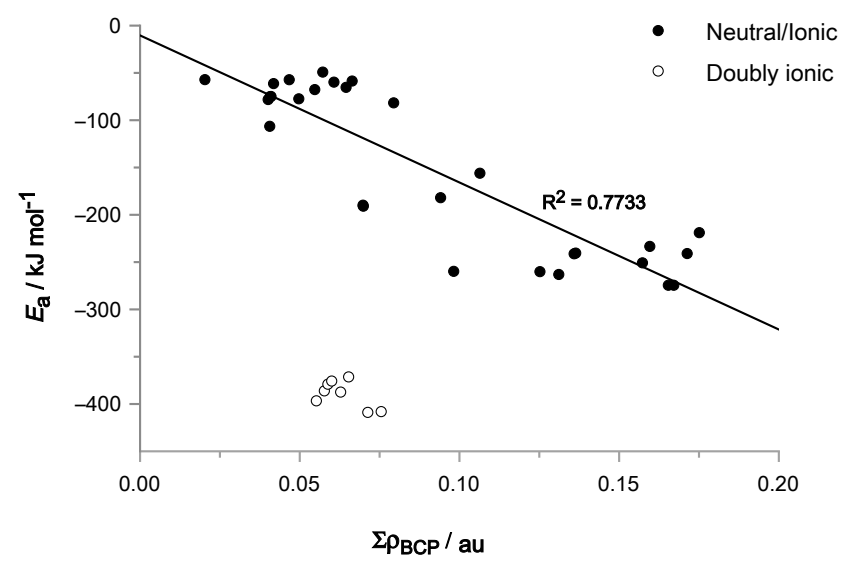

50 Figure 13. Plot of $E_{\mathrm{a}}$ and $\Sigma \rho_{\mathrm{BCP}}$ values for the complexes. The cholinechloride ion pairs have not been included in the fit.

Local methods of characterising $\mathrm{H}$-bonding (based on $\rho_{\mathrm{BCP}}$ or $\left.E^{(2)}\right)$ are more appropriate for H-bonding in ILs. However, it ${ }_{55}$ should be recognised that $\rho_{\mathrm{BCP}}$ or $E^{(2)}$ only "measure" a component of the total H-bond which will include electrostatic, dispersion, polarisation and repulsive contributions. As a rough estimate, Equation 2, from the linear regression analysis in Figure 13, can be used to gauge the extent to which the ion pairs ${ }_{60}$ deviate from the relationship between $\Sigma \rho_{\mathrm{BCP}}$ and $E_{\mathrm{a}}$. The average $\Sigma \rho_{\mathrm{BCP}}$ of the $\mathrm{ChCl}$ ion pairs is 0.0633 au. Using Equation 2, an average $E_{\mathrm{a}}$ of $-109 \mathrm{~kJ} \mathrm{~mol}^{-1}$ would be predicted. The actual mean $E_{\mathrm{a}}$ of the ion pairs is $-389 \mathrm{~kJ} \mathrm{~mol}^{-1}$. Thus, there is a difference of $-280 \mathrm{~kJ} \mathrm{~mol}^{-1}$, suggesting that $\approx 72 \%$ of the interaction energy of a ${ }_{65} \mathrm{ChCl}$ ion pair is ionic.

$$
E_{a}=-1554.3\left(\sum \rho_{B C P}\right)-10.37
$$

Equation 2

\section{Conclusions}

Relative to their neutral and ionic counterparts, doubly ionic $70 \mathrm{H}$-bonds have been poorly explored. DESs provide good exemplars of systems featuring neutral, ionic and doubly ionic $\mathrm{H}-$ 
bonds. In this article we have examined pairwise interactions, and in particular the H-bonds, within the archetypal DES: $\mathrm{ChCl}-$ urea. $\mathrm{H}$-bonds are identified and characterised between; $\mathrm{ChCl}$ ion pairs (doubly ionic $\mathrm{H}$-bonds), urea and chloride (anionic $\mathrm{H}$ 5 bonds), choline and urea (cationic H-bonds) and urea-urea (neutral H-bonds).

The association energy for the lowest energy structure of each pairwise species reflects the expected ordering based on gross Coulomb (point charges, dipoles) contributions ( $\mathrm{Ch}-\mathrm{Cl}>\mathrm{Cl}$-urea ${ }_{10}>$ Ch-urea $>$ urea-urea). For all of the pairs examined structural variety was present, and the detailed ordering between conformers could not be predicted based on gross Coulomb contributions. Thus, it is clear that the detailed (atomic level) anisotropic distribution of charge within the ionic species is 15 important. One might expect the number of H-bonds to be maximised in a gas-phase dimer, however it was found that while the number of H-bonds was large, it was not always maximised in the lowest energy conformers. Thus, it is evident that there is a fine balance between facilitating stabilising (close range) ${ }_{20}$ Coulombic interactions and maximising H-bonding, both appear to be structural drivers.

172 individual H-bonds have been examined here and organised according to different types. It is clear that a very large number of $\mathrm{H}$-bonds can form within the DES. A key outcome of 25 this study is a recognition of the variety of H-bonds present, the DES contains an "alphabet soup" of H-bond types: $\mathrm{OH} \cdots \mathrm{O}=\mathrm{C}$, $\mathrm{NH} \cdots \mathrm{O}=\mathrm{C}, \quad \mathrm{OH} \cdots \mathrm{Cl}, \mathrm{NH} \cdots \mathrm{Cl}, \mathrm{OH} \cdots \mathrm{NH}, \mathrm{CH} \cdots \mathrm{Cl}, \mathrm{CH} \cdots \mathrm{O}=\mathrm{C}$, $\mathrm{NH} \cdots \mathrm{OH}$ and $\mathrm{NH}^{\cdots} \cdots \mathrm{NH}$ interactions have all been identified. This is in contrast to traditional molecular solvents which typically 30 have a very homogenous $\mathrm{H}$-bonding character (i.e. the H-bonds are all of the same type, such as $\mathrm{OH} \cdots \mathrm{O}$ in water or alcohols). The introduction of many different $\mathrm{H}$-bond types could be expected to increase the entropy of the system, and thus favour eutectic formation.

35 Furthermore, within each type of H-bond, there is considerable variation in strength; the energy range covered by many of the $\mathrm{H}$ bonds is very similar. Multiple low energy conformers also show evidence of a competition between a smaller number of stronger $\mathrm{H}$-bonds and larger number of weaker H-bonds, this network of $40 \mathrm{H}$-bonds may help to structure the liquid. Overall, the ChCl-urea DES exhibits a particularly diverse range of $\mathrm{H}$-bonding all within the same liquid environment.

Interaction with the choline cation with chloride or urea generates a wide range of low energy structures. H-bonds can ${ }_{45}$ form with both the ammonium head group and/or with the more traditional $\mathrm{OH}$ functionality on the alkyl chain. The doubly ionic character of the $\mathrm{ChCl}$ system facilitates the formation of $\mathrm{CH}$ based $\mathrm{H}$-bonds that would be too weak to register in a neutral system. Evidence has been obtained of a recurring tripodal $\mathrm{H}$ ${ }_{50}$ bond motif formed from three $\mathrm{CH}$ donors interacting with the chloride. Surprisingly, the (often ignored) tripodal H-bond motif forms a stronger $\mathrm{H}$-bonding interaction than the more traditional $\mathrm{OH}$ donor. Moreover, using covalent descriptors, doubly ionic $\mathrm{CH} \cdots \mathrm{Cl}$ interactions are revealed to be competitive with anionic ${ }_{55} \mathrm{NH} \cdots \mathrm{Cl}$ interactions, although typically $\mathrm{NH}$ is considered a better $\mathrm{H}$-bond donor than $\mathrm{CH}$.

Due to the dominant Coulombic attraction between the oppositely charges ions, it has been suggested that total association energies, such as $E_{a}$, cannot be employed to quantify ${ }_{60}$ doubly ionic H-bonds. Rather, local descriptors, such as MOinteractions, $\rho_{\mathrm{BCP}}$ and $E^{(2)}$ should be employed. ${ }^{7}$ Our results support this interpretation, a poor correlation was found between these local descriptors $\left(\rho_{\mathrm{BCP}}\right.$ and $\left.E^{(2)}\right)$ and $E_{a}$. Nevertheless, a relationship between $\Sigma \rho_{\mathrm{BCP}}$ and $E_{a}$, for non- doubly ionic $\mathrm{H}-$ ${ }_{65}$ bonds was obtained, allowing us to make a rough estimate of the ionic $\approx 280 \mathrm{~kJ} \mathrm{~mol}^{-1}(72 \%)$ vs H-bonding $\approx 109 \mathrm{~kJ} \mathrm{~mol}^{-1}(28 \%)$ contributions to the average association energy of $\mathrm{ChCl}$.

In rationalising the formation of a eutectic at a 1:2 ratio, it is natural to suggest the presence of symmetrically complexed $70\left[2 \mathrm{urea}^{\bullet} \mathrm{Cl}\right]^{-}$anion, where the urea acts as a H-bond donor. It is anticipated that the negative charge becomes delocalised and the complexed anion interacts only weakly with the choline cation leading to a lower melting point.

However, it is important to recognise that urea acts as both a $75 \mathrm{H}$-bond donor and $\mathrm{H}$-bond acceptor. Urea can $\mathrm{H}$-bond with chloride to form an anionic complex or with choline to form a cationic complex, and both are favoured. The ability of urea to accept or donate small amounts of charge is important.

The charge distribution within the new species appears to be 80 that of a cation or anion coordinated by urea, not of a complex with delocalised charge. The MOs show limited delocalisation and charge transfer is less than that obtained for the $\mathrm{ChCl}$ ionpairs, which are not considered to be neutral (charge delocalised) clusters. Thus, urea may act more as a "spacer" increasing the 85 charge separation of ions within the liquid.

Moreover, there is evidence that formation of $2 \mathrm{urea}[\mathrm{Cl}]^{-}$is not necessarily exclusively favoured. While the formation of a urea $[\mathrm{Cl}]^{-}$species is found to be stabilising, the formation of a urea[choline $]^{+}$species is competitive with the formation of $902 \mathrm{urea}[\mathrm{Cl}]^{-}$. The strongest $\mathrm{H}$-bond identified here is the cationic choline-urea $\mathrm{OH} \cdots \mathrm{O}=\mathrm{C}$ H-bond, not the chloride-urea $\mathrm{NH} \cdots \mathrm{Cl} \mathrm{H}-$ bond. Our results indicate that on average, the individual $\mathrm{H}-$ bonds between urea and choline, or even urea with another urea, are stronger than those with the chloride.

95 Thus it may be reasonable to suggest an alternative picture to the formation of a $\left[\mathrm{Cl}(\text { urea })_{2}\right]^{-}$complexed anion leading to a reduced cation-anion interaction. On the addition of urea to $\mathrm{ChCl}$, the formation of cluster from the coordinated ions; urea $[\mathrm{Ch}]^{+}$and urea $[\mathrm{Cl}]^{-}$which exhibit a reduced Coulombic 100 interaction relative to $\mathrm{ChCl}$. It is also evident that there is substantial H-bonding, with an "alphabet soup" of H-bonds, that can vary in strength and number, having significant potential to impact on the entropy of the system.

\section{Acknowledgments}

${ }_{105}$ C.R.A gratefully acknowledges Rio Tinto for $\mathrm{PhD}$ sponsorship and Dr Matthew Clough for helpful discussions.

\section{Notes and references}

Department of Chemistry, Imperial College London, London, SW7 2AZ, UK.E-mail:p.hunt@imperial.ac.uk

110

$\dagger$ Electronic Supplementary Information (ESI) available: [Relative energies of all species, with and without ZPE and BSSE corrections. Relative Gibbs free energies of all species. Selected H-bond data $(\mathrm{H}-$ bond lengths, $E^{(2)}, \rho_{\mathrm{BCP}}, \nabla^{2} \rho_{\mathrm{BCP}}$ and $\mathrm{H}_{\mathrm{c}}$ values) for all identified H-bonds. 115 Partial charge analysis of the choline cation. More detailed comparison of 
the two choline conformers. Estimation of the Coulombic interaction within ion pairs. Comment on the geometries of urea-chloride clusters. Figures showing: correlation between $\rho_{\mathrm{BCP}}$ and $\nabla^{2} \rho_{\mathrm{BCP}}$, close intramolecular $\mathrm{CH} \cdots \mathrm{O}$ contacts within gauche choline and gauche $\mathrm{N}, \mathrm{N}$ dimethylethanolamine, QTAIM molecular graph of the chloroform-Cl complex, conformers of urea, actual $n$.urea-chloride clusters, the HOMO1 of selected $n$.urea-chloride complexes and a plot of $E^{(2)}$ against $\rho_{\mathrm{BCP}}$ for all identified H-bonds.] See DOI: 10.1039/b000000x/

10 1. E. Arunan, R. Desiraju Gautam, A. Klein Roger, J. Sadlej, S. Scheiner, I. Alkorta, C. Clary David, H. Crabtree Robert, J. Dannenberg Joseph, P. Hobza, G. Kjaergaard Henrik, C. Legon Anthony, B. Mennucci and J. Nesbitt David, in Pure and Applied Chemistry, 2011, vol. 83, p. 1619.

15 2. T. Steiner, Angewandte Chemie International Edition, 2002, 41, 4876.

3. E. Arunan, R. Desiraju Gautam, A. Klein Roger, J. Sadlej, S. Scheiner, I. Alkorta, C. Clary David, H. Crabtree Robert, J. Dannenberg Joseph, P. Hobza, G. Kjaergaard Henrik, C. Legon Anthony, B. Mennucci and J. Nesbitt David, in Pure and Applied Chemistry, 2011, vol. 83, p. 1637.

4. S. J. Grabowski, Chemical Reviews, 2011, 111, 2597-2625.

5. M. Meot-Ner, Chemical Reviews, 2005, 105, 213-284.

6. M. Meot-Ner, Chemical Reviews, 2012, 112, PR22-PR103.

25 7. P. A. Hunt, C. R. Ashworth and R. P. Matthews, Chemical Society Reviews, 2015, 44, 1257-1288.

8. T. Welton, Wasserscheid, P., ed., Ionic Liquids in Synthesis, WileyVCH, Weinheim, 2008

9. J. P. Hallett and T. Welton, Chemical Reviews, 2011, 111, 35083576.

10. B. Kirchner, ed., Ionic Liquids, Springer, 2009.

11. K. Fumino, T. Peppel, M. Geppert-Rybczynska, D. H. Zaitsau, J. K. Lehmann, S. P. Verevkin, M. Kockerling and R. Ludwig, Physical Chemistry Chemical Physics, 2011, 13, 14064-14075.

35 12. M. Kohagen, M. Brehm, Y. Lingscheid, R. Giernoth, J. Sangoro, F. Kremer, S. Naumov, C. Iacob, J. Kärger, R. Valiullin and B. Kirchner, The Journal of Physical Chemistry B, 2011, 115, 1528015288 .

13. K. Fumino, S. Reimann and R. Ludwig, Physical Chemistry Chemical Physics, 2014, 16, 21903-21929.

14. P. A. Hunt, The Journal of Physical Chemistry B, 2007, 111, 48444853.

15. E. I. Izgorodina and D. R. MacFarlane, The Journal of Physical Chemistry B, 2011, 115, 14659-14667.

45 16. I. Skarmoutsos, T. Welton and P. A. Hunt, Physical Chemistry Chemical Physics, 2014, 16, 3675-3685.

17. R. P. Matthews, T. Welton and P. A. Hunt, Physical Chemistry Chemical Physics, 2015, 17, 14437-14453.

18. K. Haerens, E. Matthijs, K. Binnemans and B. Van der Bruggen, Green Chemistry, 2009, 11, 1357-1365.

19. A. P. Abbott, G. Capper, D. L. Davies, R. K. Rasheed and V. Tambyrajah, Chemical Communications, 2003, 70-71.

20. A. P. Abbott, J. C. Barron, K. S. Ryder and D. Wilson, Chemistry A European Journal, 2007, 13, 6495-6501.

55 21. E. L. Smith, A. P. Abbott and K. S. Ryder, Chemical Reviews, 2014, DOI: $10.1021 / \mathrm{cr} 300162 \mathrm{p}$

22. A. P. Abbott, D. Boothby, G. Capper, D. L. Davies and R. K. Rasheed, Journal of the American Chemical Society, 2004, 126, 9142-9147.

60 23. A. P. Abbott, R. C. Harris and K. S. Ryder, The Journal of Physical Chemistry B, 2007, 111, 4910-4913.

24. A. P. Abbott, R. C. Harris, K. S. Ryder, C. D'Agostino, L. F. Gladden and M. D. Mantle, Green Chemistry, 2011, 13, 82-90.

25. S. Xia, G. A. Baker, H. Li, S. Ravula and H. Zhao, RSC Advances, 2014, 4, 10586-10596.

26. Q. Zhang, K. De Oliveira Vigier, S. Royer and F. Jerome, Chemical Society Reviews, 2012, 41, 7108-7146.

27. a). S. L. Perkins, P. Painter and C. M. Colina, The Journal of Physical Chemistry B, 2013, 117, 10250-10260. b). S. L. Perkins, P. Painter and C. M. Colina, Journal of Chemical \& Engineering Data, 2014, 59, 3652-3662.
28. a). H. Sun, Y. Li, X. Wu and G. Li, J Mol Model, 2013, 19, 24332441. b). G. García, M. Atilhan and S. Aparicio, Journal of Molecular Liquids, 2015, 211, 506-514.

75 29. a). H. Li, Y. Chang, W. Zhu, C. Wang, C. Wang, S. Yin, M. Zhang and H. Li, Physical Chemistry Chemical Physics, 2015, 15, 2872928742. b). G. García, M. Atilhan and S. Aparicio, International Journal of Greenhouse Gas Control, 2015, 39, 62-73. c). G. García, M. Atilhan and S. Aparicio, Chemical Physical Letters, 2015, 634, 151-155. d). J. M. Rimza and L. René Corrales, Computational and Theoretical Chemistry, 2012, 987, 57-61. e). C. Zhang, Y. Jia, Y. Jing, H. Wang and K. Hong, Journal of Molecular Modelling, 2014, 20:2374.

30. G. R. Desiraju, Accounts of Chemical Research, 2002, 35, 565-573.

85 31. G. A. Jeffrey, An Introduction to Hydrogen Bonding Oxford University Press, 1997

32. U. Koch and P. L. A. Popelier, The Journal of Physical Chemistry, 1995, 99, 9747-9754.

33. R. Parthasarathi and V. Subramanian, in Hydrogen Bonding-New

90 Insights, ed. S. Grabowski, Springer Netherlands, 2006, vol. 3, ch. 1, pp. $1-50$.

34. F. L. Weinhold, Clark, Valency and Bonding, A Natural Bond Orbital Donor-Acceptor Perspective, Cambridge University Press Cambridge, 2005.

95 35. I. Rozas, I. Alkorta and J. Elguero, The Journal of Physical Chemistry A, 1999, 103, 8861-8869.

36. R. D. Gaussian 09, G. W. T. M. J. Frisch, H. B. Schlegel, G. E. Scuseria,, J. R. C. M. A. Robb, G. Scalmani, V. Barone, B. Mennucci,, H. N. G. A. Petersson, M. Caricato, X. Li, H. P. Hratchian,, J. B. A. F. Izmaylov, G. Zheng, J. L. Sonnenberg, M. Hada, K. T. M. Ehara, R. Fukuda, J. Hasegawa, M. Ishida, T. Nakajima, O. K. Y. Honda, H. Nakai, T. Vreven, J. A. Montgomery, Jr.,, F. O. J. E. Peralta, M. Bearpark, J. J. Heyd, E. Brothers, V. N. S. K. N. Kudin, T. Keith, R. Kobayashi, J. Normand, A. R. K. Raghavachari, J. C. Burant, S. S. Iyengar, J. Tomasi,, N. R. M. Cossi, J. M. Millam, M. Klene, J. E. Knox, J. B. Cross,, C. A. V. Bakken, J. Jaramillo, R. Gomperts, R. E. Stratmann,, A. J. A. O. Yazyev, R. Cammi, C. Pomelli, J. W. Ochterski,, K. M. R. L. Martin, V. G. Zakrzewski, G. A. Voth,, J. J. D. P. Salvador, S. Dapprich, A. D. Daniels,, J. B. F. O. Farkas, J. V. Ortiz, J. Cioslowski, and G. and D. J. Fox, Inc., Wallingford CT, 2013.

37. A. D. Becke, The Journal of Chemical Physics, 1993, 98, 56485652 .

115 38. C. Lee, W. Yang and R. G. Parr, Physical Review B, 1988, 37, 785789.

39. S. Grimme, Journal of Computational Chemistry, 2006, 27, 17871799.

40. L. F. Pacios, O. Gálvez and P. C. Gómez, The Journal of Chemical Physics, 2005, 122, -

41. S. F. Boys and F. Bernardi, Molecular Physics, 1970, 19, 553-566.

42. J. K. B. NBO 5.9. E. D. Glendening, A. E. Reed, J. A. B. J. E. Carpenter, C. M. Morales, and F. Weinhold, U. o. W. (Theoretical Chemistry Institute and W. Madison, 2009); http://www.chem.wisc.edu/ nbo5.

43. C. M. Breneman and K. B. Wiberg, Journal of Computational Chemistry, 1990, 11, 361-373.

44. T. A. K. AIMAll (Version 14.06.21), TK Gristmill Software, Overland Park KS, USA, 2014 (aim.tkgristmill.com).

130 45. L. Tanzi, P. Benassi, M. Nardone and F. Ramondo, The Journal of Physical Chemistry A, 2014, 118, 12229-12240.

46. P. Partington, J. Feeney and A. S. V. Burgen, Molecular Pharmacology, 1972, 8, 269-277.

47. Y. Terui, M. Ueyama, S. Satoh and K. Tori, Tetrahedron, 1974, 30, 1465-1471.

48. S. Zahn, F. Uhlig, J. Thar, C. Spickermann and B. Kirchner, Angewandte Chemie International Edition, 2008, 47, 3639-3641.

49. R. E. Rosenfield and P. Murray-Rust, Journal of the American Chemical Society, 1982, 104, 5427-5430.

140 50. H. Niedermeyer, C. Ashworth, A. Brandt, T. Welton and P. A. Hunt, Physical Chemistry Chemical Physics, 2013, 15, 11566-11578.

51. U. Adhikari and S. Scheiner, The Journal of Physical Chemistry A, 2013, 117, 10551-10562. 
52. A. S. Davies, W. O. George and S. T. Howard, Physical Chemistry Chemical Physics, 2003, 5, 4533-4540.

53. S. Tsuzuki, W. Shinoda, M. S. Miran, H. Kinoshita, T. Yasuda and M. Watanabe, The Journal of Chemical Physics, 2013, 139, 174504.

5 54. J. Rigby and E. I. Izgorodina, Physical Chemistry Chemical Physics, $2013,15,1632-1646$

55. J. A. Platts, H. Maarof, K. D. M. Harris, G. K. Lim and D. J. Willock, Physical Chemistry Chemical Physics, 2012, 14, 11944 11952.

10 56. P. D. Godfrey, R. D. Brown and A. N. Hunter, Journal of Molecular Structure, 1997, 413-414, 405-414.

57. A. Gobbi and G. Frenking, Journal of the American Chemical Society, 1993, 115, 2362-2372.

58. A. Masunov and J. J. Dannenberg, The Journal of Physical Chemistry A, 1998, 103, 178-184.

59. J. Demaison, A. G. Császár, I. Kleiner and H. Møllendal, The Journal of Physical Chemistry A, 2007, 111, 2574-2586.

60. A. Masunov and J. J. Dannenberg, The Journal of Physical Chemistry B, 2000, 104, 806-810.

20 61. J. Hjortas and H. Sorum, Acta Crystallographica Section B, 1971, $27,1320-1323$.

62. L. Ge, L. Bernasconi and P. Hunt, Physical Chemistry Chemical Physics, 2013, 15, 13169-13183.

63. I. Rozas, I. Alkorta and J. Elguero, The Journal of Physical Chemistry B, 2004, 108, 3335-3341.

64. I. Rozas, I. Alkorta and J. Elguero, Organic \& Biomolecular Chemistry, 2005, 3, 366-371.

65. I. Rozas, Physical Chemistry Chemical Physics, 2007, 9, 2782-2790. 